\title{
A Voltage-Clamp Analysis of Gene-Dosage Effects of the Shaker Locus on Larval Muscle Potassium Currents in Drosophila
}

\author{
Frank Nelson Haugland and Chun-Fang Wu \\ Departments of Biology and of Physiology and Biophysics, University of lowa, lowa City, lowa 52242
}

\begin{abstract}
Mutations of the Shaker (Sh) locus of Drosophila reduce, eliminate, or otherwise alter a transient potassium current, $I_{A}$, in muscle. Recent molecular studies indicate that the $S h$ locus produces several proteins by alternative splicing, but the relationships of the variety of Sh gene products to $I_{A}$ channels in the various excitable membranes still remain to be determined. In Drosophila, many enzymes have been shown to exhibit gene-dosage effects; their amounts vary in direct proportion to the number of structural genes present. We describe a physiological isolation of $I_{A}$ in larval muscle which allowed precise quantification of gene-dosage effects on $I_{A}$ in Sh heterozygotes and aneuploids. We found that doubling the number of $S h$ genes in aneuploids increased $I_{A}$ to twice that of normal, consistent with the notion that the $S h$ locus encodes the entire $I_{A}$ channel in larval muscle. We further examined heterozygous combinations of different $S h$ mutations for evidence of interactions among Sh gene products within the $I_{A}$ channel, which may yield clues to the possible subunit composition of the channel. Combinations among 5 Sh mutations plus their normal counterpart followed a simple gene-dosage effect; in each case the resulting $I_{A}$ was about the average of the homozygous currents, compatible with the notion of additive contributions from 2 independent populations of $I_{A}$ channels. Two additional Sh mutations caused pronounced departures from the simple dosage effect; the amplitude of $I_{A}$ in heterozygotes was significantly smaller than that expected from gene dosage, a strong dominant effect attributable to interactions among protein subunits. These contrasting observations may be accounted for by certain hetero- or homo-multimeric arrangements of $S h$ products in the $I_{A}$ channel.
\end{abstract}

Defective ion channels that cause altered membrane excitability have been detected in a number of Drosophila behavioral mutants (Ganetzky and Wu, 1986; Salkoff and Tanouye, 1986; Tanouye et al., 1986; Papazian et al., 1988). The Shaker (Sh) mutants, originally isolated on the basis of a vigorous leg-shaking behavior under ether anesthesia (Kaplan and Trout, 1969),

\footnotetext{
Received Sept. 26, 1989; accepted Nov. 7, 1989.

We thank Drs. P. A. Getting and R. W. Joyner for their help during the course of this work and Drs. D. Mohler and M. Gorczyca for comments on the manuscript. We also thank Dr. L. Timpe for communicating results before publication and Drs. B. Ganetzky, M. Tanouye, and L. Salkoff for providing mutant stocks. The results presented here were submitted in partial fulfillment of requirements for the Ph.D degree (F.N.H.) from the University of Iowa. This work was supported by NIH grants NS00675 and NS18500 to C.-F.W.

Correspondence should be addressed to Dr. Chun-Fang Wu, Department of Biology, University of Iowa, Iowa City, IA 52242.

Copyright (c) 1990 Society for Neuroscience $0270-6474 / 90 / 041357-15 \$ 02.00 / 0$
}

have been subject to the most intensive investigations. The neuromuscular junction of $S h$ larvae was found to exhibit repetitive firing of motor axons coupled with prolonged neurotransmitter release (Jan et al., 1977; Ganetzky and Wu, 1982, 1983). Subsequent intracellular recordings from adult cervical giant axons revealed abnormally prolonged action potentials (Tanouye et al., 1981; Tanouye and Ferrus, 1985). The application of voltage-clamp technique has demonstrated alterations in the transient $\mathrm{K}^{+}$current, $\mathrm{I}_{\mathrm{A}}$, in adult (Salkoff and Wyman, 1981; Salkoff, 1983), larval (Wu et al., 1983; Wu and Haugland, 1985), and embryonic (Zagotta et al., 1988) muscle.

This study was originally inspired by the suggestion that the $S h$ locus consists of a gene complex of closely linked functions (Tanouye et al., 1981; Tanouye and Ferrus, 1985). Experiments were designed to detect interactions among different $S h$ gene products in heterozygous individuals. Since the completion of our experiments (Haugland and Wu, 1986; Haugland, 1987), molecular data have become available indicating that the $S h$ locus contains a complex transcription unit producing, by alternative splicing, a family of related proteins (Baumann et al., 1987; Kamb et al., 1987, 1988; Papazian et al., 1987; Pongs et al., 1988; Schwar7 et al., 1988). To date, no additional putative channel genes in the $S h$ region have been identified by molecular techniques. Nevertheless, the physiological data described in this paper indeed suggest interactions among $S h$ proteins and could therefore be used to assess the possible involvement of different $S h$ splicing variants within the $\mathrm{I}_{\mathrm{A}}$ channel.

The $S h$ messages have been expressed in Xenopus oocytes to generate active $\mathrm{K}^{+}$channels, providing a powerful approach to the structure-function analysis of individual $S h$ splicing variants (Iverson et al., 1988; Timpe et al., 1988a, b). However, for some channels with heteromultimeric subunit composition in situ, a single subunit species can form functional homomeric channels in the oocyte expression system (Boulter et al., 1987; Auld et al., 1988; Blair et al., 1988). In addition, it is known that the $S h$ channels expressed in oocytes exhibit abnormal propertics (MacKinnon et al., 1988). Thus, several questions regarding the functional role of the $S h$ products in the native $\mathrm{I}_{\Lambda}$ channels still remain to be resolved by using in situ preparations with a combination of molecular and electrophysiological techniques: How many distinct functional components within $I_{A}$ channels are encoded by the $S h$ locus? For the different $S h$ gene products, how is their expression regulated in various excitable membranes and what is their stoichiometric representation in the assembled $I_{A}$ channel? Are there different types of $I_{A}$ channels that consist of different combinations of the $S h$ gene products?

Many mutations of the $S h$ locus are now available and their effects on $I_{A}$ range from complete elimination or simple reduc- 
Table 1. Active membrane properties of larval muscles in Sh homozygotes and heteronygotes

\begin{tabular}{|c|c|c|c|c|}
\hline & $S h^{+}$ & $S h^{5}$ & $S h^{r K 0120}$ & $S h^{E 62}$ \\
\hline & $4.78 \pm 0.16(15)$ & $3.24 \pm 0.23(10)$ & $3.61 \pm 0.10(12)^{b}$ & $2.58 \pm 0.15(10)$ \\
\hline & & $3.54 \pm 0.11(28)$ & $4.25 \pm 0.14(23)$ & $3.02 \pm 0.09$ \\
\hline & & $2.29 \pm 0.15(13)$ & $2.68 \pm 0.16(8)$ & $2.01 \pm 0.19(9)$ \\
\hline & & & $3.00 \pm 0.14(21)$ & $1.78 \pm 0.08(25)$ \\
\hline \multirow[t]{2}{*}{$S h^{+}$} & $0.75 \pm 0.044(15)$ & & $3.71 \pm 0.26(8)$ & $2.38 \pm 0.14(13)$ \\
\hline & & & & $2.49 \pm 0.13(20)$ \\
\hline \multirow[t]{2}{*}{$S h^{5}$} & $0.39 \pm 0.044(10)$ & $0.29 \pm 0.023(13)$ & & $1.26+0.08(12)$ \\
\hline & $0.52 \pm 0.025(28)$ & & & \\
\hline \multirow[t]{2}{*}{$S h^{r K 0120}$} & $0.51 \pm 0.025(12)^{a}$ & $0.37 \pm 0.027(8)$ & $0.53 \pm 0.067(8)$ & \\
\hline & $0.64 \pm 0.038(23)$ & $0.41 \pm 0.032(21)$ & & \\
\hline \multirow[t]{2}{*}{$S h^{E 62}$} & $0.37 \pm 0.029(10)^{a}$ & $0.24 \pm 0.046(9)$ & $0.33 \pm 0.023(13)$ & $0.20 \pm 0.015(12)$ \\
\hline & $0.48 \pm 0.024(27)$ & $0.25 \pm 0.014(25)$ & $0.37 \pm 0.031(20)$ & \\
\hline \multirow[t]{2}{*}{$S h^{M}$} & $0.35 \pm 0.033(10)$ & $0.15 \pm 0.016(6)$ & $0.25 \pm 0.027(11)$ & $0.10 \pm 0.011(4)$ \\
\hline & $0.38 \pm 0.027(20)$ & $0.15 \pm 0.014(18)$ & $0.27 \pm 0.037(13)$ & $0.10 \pm 0.010(17)$ \\
\hline \multirow[t]{2}{*}{$S h^{\kappa 8 z a}$} & $0.35 \pm 0.037(7)$ & $0.12 \pm 0.026(4)$ & $0.29 \pm 0.013(4)$ & $0.11 \pm 0.008(10)$ \\
\hline & $0.38 \pm 0.030(16)$ & $0.15 \pm 0.016(14)$ & $0.27 \pm 0.045(9)$ & $0.10 \pm 0.011(13)$ \\
\hline \multirow[t]{2}{*}{$S h^{K S / 33}$} & $0.06 \pm 0.006(10)^{b}$ & $0.07 \pm 0.010(5)^{b}$ & $0.05 \pm 0.009(8)^{b}$ & $0.04 \pm 0.004(9)^{a}$ \\
\hline & $0.38 \pm 0.027(20)$ & $0.15 \pm 0.014(18)$ & $0.27 \pm 0.037(13)$ & $0.10 \pm 0.010(17)$ \\
\hline \multirow[t]{3}{*}{$S h^{102}$} & $0.28 \pm 0.021(14)^{a}$ & $0.07 \pm 0.007(10)^{b}$ & $0.15 \pm 0.015(11)^{a}$ & $0.03 \pm 0.004(10)^{b}$ \\
\hline & $0.38 \pm 0.027(20)$ & $0.15 \pm 0.014(18)$ & $0.27 \pm 0.037(13)$ & $0.10 \pm 0.010(17)$ \\
\hline & $S h^{+}$ & $S h^{s}$ & $S h^{\text {rolzo }}$ & $S h^{E 62}$ \\
\hline
\end{tabular}

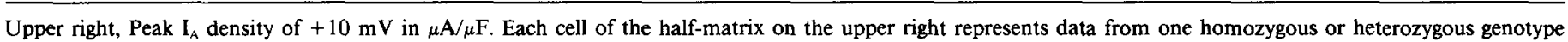

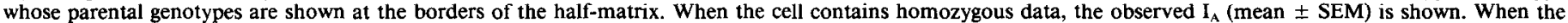

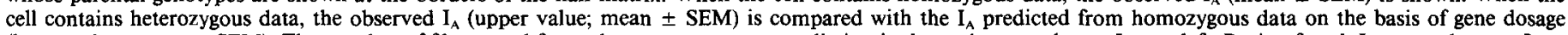

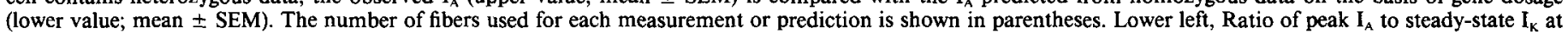

tion in amplitude, to altered biophysical properties. The above questions may be explored in situ by combining these $S h$ mutations in a heterozygous individual. Drosophila is a diploid organism in which both copies of a gene contribute equal amounts of gene products (see review by Stewart and Merriam, 1980). Thus, in flies heterozygous for $S h$ alleles, a departure from the simple additive effect of gene dosage may indicate interaction between gene products. Moreover, it is also possible to study the effects of extra copies of genes in aneuploids (Lindsley and Grell, 1968; Stewart and Merriam, 1980).

We show that a duplication of the $S h$ region produced twice the normal amplitude of $I_{A}$, supporting the idea that the $S h$ locus codes for the entire $I_{A}$ channel. In addition, heterozygotic combinations among $S h^{+}, S h^{5}, S h^{M}, S h^{K 82 a}, S h^{E 62}$, and $S h^{\text {K0120 }}$ follow a simple gene-dosage effect, with the observed current being about the average of the homozygous currents. With different assumptions, the simple dosage effect can be explained by several possible multimeric models of $S h$ gene products within the $\mathrm{I}_{\mathrm{A}}$ channel (see Discussion). In contrast, 2 other mutations, $S h^{K S 133}$ and $S h^{102}$, cause decreases in $\mathrm{I}_{\mathrm{A}}$ significantly different from that expected from simple gene-dosage effects, suggesting abnormal $S h$ products capable of interfering with other $S h$ proteins within a subunit assembly.

Comparisons with previously published data from different excitable membranes reveal considerable discrepancies in the phenotypes of certain $S h$ mutations and their heterozygotes. This indicates that $I_{A}$ channel structure and function may vary in a tissue-specific manner and supports the notion that the diversity of $\mathrm{K}^{+}$channels arises from combinations of common as well as distinct functional components (Wu and Haugland, 1985; Wu and Ganetzky, 1986; Kamb et al., 1988; Pongs et al., 1988; Timpe et al., 1988b). Preliminary accounts of some of the results reported here have appeared previously (Haugland and $\mathrm{Wu}, 1986$ ).

\section{Materials and Methods}

Mutants, crosses, and nomenclature. The wild-type strain Canton-S of Drosophila melanogaster was uscd for the charactcrization of normal membrane currents. Normal larvae are designated $S h^{+}$. Seven different mutant $S h$ strains are characterized; 6 of these strains $\left(S h^{K S 133}, S h^{102}\right.$, $S h^{M}, S h^{5}, S h^{r K 0120}$, and $S h^{E \sigma 2}$ ) were obtained from the collection of Dr. S. Benzer at the California Institute of Technology. Five of these mutations $\left(S h^{K S 133}, S h^{102}, S h^{5}, S h^{r K 0120}\right.$, and $\left.S h^{E 62}\right)$ have been mapped via recombination to position 57.0 of the $X$ chromosome (see Tanouye et al., 1986, for details). Some of the $S h^{r k 0 t z o}$ stocks had previously been shown to carry a second mutation, ether á go-go (Ganetzky and $\mathrm{Wu}$, 1983), which was removed via recombination in this study. A seventh mutant strain, $S h^{K 82 a}$, provided by Dr. B. Ganetzky at the University of Wisconsin, involves a chromosomal rearrangement in the $S h$ region (Schwarz et al., 1988). An additional strain, $D p(1 ; 3) J C 153$, which possesses a duplicated copy of the $S h^{+}$locus translocated onto the third chromosome (Tanouye et al., 1986), was used for genc-dosage expcriments; this strain was provided by Dr. M. Tanouye at the California Institute of Technology. To minimize influences of unidentified loci in different genetic backgrounds, each of these $S h$ mutations was examined in a Canton-S background by replacing autosomes and, in some cases, portions of the $\mathrm{X}$ chromosome away from the $S h$ locus by genetic recombination. As a further precaution, additional copies of certain strains were obtained from other investigators. One strain of $S h^{5}$ was provided by Dr. L. Salkoff at Washington University, St. Louis, and a strain of $S h^{K S 133}$ by Dr. L. Timpe at the Howard Hughes Medical Institute, San Francisco. Both strains yielded results consistent with those reported here.

Heterozygous female larvae (possessing 2 different $S h$ mutations and denoted, for example, $S h^{K S / 33} / S h^{M}$ ) were obtained by mating a single virgin mutant female with 5-10 males of a different $S h$ mutation. When multiple larvae of a given heterozygous (or aneuploid) genotype were examined (cf. Table 1), each was the result of an independent mating. For descriptive purposes, we refer to $S h$ mutations that eliminate $I_{A}$ as "null" alleles as opposed to those with residual $\mathrm{I}_{\mathrm{A}}$ as "leaky." 
Table 1. Continued

\begin{tabular}{|c|c|c|c|c|}
\hline$S h^{M}$ & $S h^{K 82 a}$ & $S h^{K S / 33}$ & $S h^{102}$ & \\
\hline $2.49 \pm 0.07(10)$ & $2.46 \pm 0.21(7)$ & $0.52 \pm 0.04(10)^{b}$ & $1.75 \pm 0.10(14)^{b}$ & $S h^{+}$ \\
\hline $2.39 \pm 0.10(20)$ & $2.39 \pm 0.10(16)$ & $2.39 \pm 0.10(20)$ & $2.39 \pm 0.10(20)$ & \\
\hline $1.08 \pm 0.06(6)$ & $1.04 \pm 0.16(4)$ & $0.49 \pm 0.06(5)^{b}$ & $0.51 \pm 0.04(10)^{b}$ & $S h^{s}$ \\
\hline $1.15 \pm 0.09(18)$ & $1.15 \pm 0.09(14)$ & $1.15 \pm 0.09(18)$ & $1.15 \pm 0.09(18)$ & \\
\hline $1.74 \pm 0.17(11)$ & $1.76 \pm 0.04(4)$ & $0.29 \pm 0.05(8)^{b}$ & $0.89 \pm 0.08(11)^{b}$ & $S h^{\text {rKotzo }}$ \\
\hline $1.86 \pm 0.14(13)$ & $1.86 \pm 0.14(9)$ & $1.86 \pm 0.14(13)$ & $1.86 \pm 0.14(13)$ & \\
\hline $0.56 \pm 0.06(4)$ & $0.69 \pm 0.04(10)$ & $0.23 \pm 0.02(9)^{b}$ & $0.21 \pm 0.03(10)^{b}$ & $S h^{E 62}$ \\
\hline $0.63 \pm 0.04(17)$ & $0.63 \pm 0.04(13)$ & $0.63 \pm 0.04$ & $0.63 \pm 0.04$ & \\
\hline \multirow[t]{3}{*}{$<0.05(5)$} & $<0.05(3)$ & $<0.05(3)$ & $<0.05(4)$ & $S h^{M}$ \\
\hline & $<0.05(6)$ & $<0.05(10)$ & $<0.05(6)$ & \\
\hline & $<0.05(1)$ & N.D. & N.D. & $S h^{\kappa \delta z a}$ \\
\hline$<0.01(5)$ & & $<0.05(5)$ & N.D. & $S h^{\kappa S / 33}$ \\
\hline$<0.01(3)$ & $<0.01(1)$ & & $<0.05(5)$ & $S h^{102}$ \\
\hline \multicolumn{5}{|l|}{$<0.01(6)$} \\
\hline$<0.01(3)$ & N.D. & $<0.01(5)$ & & \\
\hline \multicolumn{5}{|l|}{$<0.01(10)$} \\
\hline$<0.01(4)$ & N.D. & N.D. & $<0.01(5)$ & \\
\hline \multicolumn{5}{|l|}{$<0.01(10)$} \\
\hline$S h^{M}$ & $S h^{\kappa 8 z a}$ & $S h^{\kappa S I 33}$ & $S h^{102}$ & \\
\hline
\end{tabular}

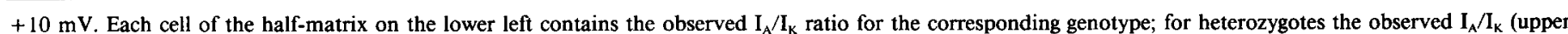
value) ratio is compared with that predicted from gene dosage (lower value). N.D., Not done.

${ }^{a} p<0.01$.

${ }^{n} p<0.001$.

Physiological measurements. Two-microelectrode voltage-clamp measurements of larval musclc mcmbranc currents and potentials were made according to previously described methods (Wu and Haugland, 1985). The preparation of mature third instar larvae was identical to that described by Jan and Jan (1976). After the segmental nerves were severed, recordings were made from identified ventral longitudinal bodywall muscle fibers from the second to the sixth abdominal segment. Data were collected exclusively from fiber no. 6, 7, 12, and 13, mostly from no. 6 and 12 (see Crossley, 1978, for nomenclature).

Inward $\mathrm{Ca}^{2+}$ currents and $\mathrm{Ca}^{2+}$-dependent $\mathrm{K}^{+}$currents (Elkins et al., 1986; Gho and Mallart, 1986; Singh and Wu, 1989) were eliminated by the use of $\mathrm{Ca}^{2+}$-free saline containing $128 \mathrm{mM} \mathrm{NaCl}, 2 \mathrm{mM} \mathrm{KCl}, 14$ $\mathrm{mM} \mathrm{MgCl}, 35 \mathrm{~mm}$ sucrose, and $0.5 \mathrm{~mm}$ EGTA. The saline was buffered with 5 mM HEPES and adjusted to $\mathrm{pH} 7.1$ by the addition of about 1.5 $\mathrm{mm} \mathrm{NaOH}$.

Measurements of membrane current and voltage were stored on a digital oscilloscope (model 4094, Nicolet Instrument Corp., Madison, WI), which was interfaced with a microcomputer (Macintosh, Apple Computer, Cupertino, CA) for data analysis. Raw data were also displayed on a storage oscilloscope (model D13, Tektronix, Beaverton, $\mathrm{OR}$ ) and photographed. All experiments were conducted at $3-5^{\circ} \mathrm{C}$.

Passive membrane properties and physiological separation of outward currents. The passive membrane properties were determined under voltage-clamp conditions for each fiber before examination of the currentvoltage $(I-V)$ relation (as shown in Fig. 1). Our previous studies indicated that voltage steps within the range between -80 and $-40 \mathrm{mV}$ elicit only passive leakage and capacitative currents (Wu et al., 1983; Wu and Haugland, 1985). Accordingly, the average current elicited by 10 identical voltage pulses from the holding potential $\left(V_{\mathrm{H}} ;-80 \mathrm{mV}\right.$ in this study) to $-40 \mathrm{mV}$ was taken. Since in our experiments the voltage clamp settled within $2 \mathrm{msec}$ of the voltage steps, the membrane capacity $\left(c_{\mathrm{m}}\right)$ was determined, therefore, by integrating the first $2.5 \mathrm{msec}$ of the capacity surge evoked by the step. The input resistance $\left(r_{\mathrm{m}}\right)$ was determined from the difference in the holding current and the current at 45 msec after initiation of the step. The membrane time constant $\left(\tau_{\mathrm{m}}\right)$ of individual fibers was estimated as the product of $r_{\mathrm{m}}$ and $c_{\mathrm{m}}$; fibers were discarded if the $\tau_{\mathrm{m}}$ was less than $20 \mathrm{msec}$.
We took advantage of the large differences in inactivation and recovery kinetics between $I_{A}$ and $I_{K}$ to achieve a physiological separation of these outward currents. When the membrane potential was held at negative potentials $\left(V_{\mathrm{H}} ;-80 \mathrm{mV}\right)$, step depolarizations elicited $2 \mathrm{com}$ ponents of active outward current (Fig. 1A). The first component was a transient outward current, $\mathrm{I}_{\mathrm{A}}$, which rose rapidly to a peak and then inactivated. A second, delayed component, $I_{K}$, rose more slowly to a plateau value. When a depolarizing prepulse (to $-20 \mathrm{mV}, 2 \mathrm{sec}$ duration) preceded the test pulse, $I_{\mathrm{A}}$ was inactivated, unmasking $\mathrm{I}_{\mathrm{K}}$ (Fig. 1A). Digital subtraction of the 2 traces yielded the amplitude and time course of inactivating current.

The amplitude and duration of the prepulse were chosen to maximize the fraction of $I_{\Lambda}$ being inactivated while minimizing contamination from inactivation of $I_{K}$. The steady-state inactivation of $I_{A}$ is essentially complete at $-20 \mathrm{mV}\left(h_{\mathrm{A}}=0\right)$ whereas the slow process of $\mathrm{I}_{\mathrm{K}}$ inactivation eventually attains only a level of $h_{\mathrm{K}}=0.5$ at this voltage (Wu and Haugland, 1985). At $4^{\circ} \mathrm{C}$, the time constant of $\mathrm{I}_{\mathrm{A}}$ inactivation at -20 $\mathrm{mV}$ is on the order of $100 \mathrm{msec}$, as compared to $20 \mathrm{sec}$ for $\mathrm{I}_{\mathrm{K}}$ inactivation (Wu and Haugland, 1985, and unpublished results). The prepulse and test pulse were separated by a 10 -msec repolarization to $-80 \mathrm{mV}$ (Fig. $1 A$ ); this brief repolarization was sufficient to close essentially all of the $I_{K}$ channels activated by the prepulse but was too short to allow significant recovery of $I_{A}$ from inactivation (Wu and Haugland, 1985). Because of these vast differences between $I_{A}$ and $I_{K}$, contamination of peak $I_{A}$ by inactivating $I_{K}$ extracted by this protocol is expected to be insignificant in the voltage range examined here. As confirmed by results from the $S h$ mutants (see below), the inactivating currents extracted indeed contained very little $I_{K}$, especially near the peaking time of $I_{A}$.

This protocol is also suitable for extracting $\mathrm{I}_{\mathrm{A}}$ in various $S h$ mutants. Previous studies have established that both kinetic and steady-state properties of $I_{K}$ are not affected by $S h$ mutations (Wu and Haugland, 1985). In addition, the rates of inactivation and recovery for the residual $I_{A}$ in $S h$ mutants are similar to normal values (Wu and I Iaugland, 1985; Haugland, 1987; see also Figs. 2 and 3).

Statistical tests of departures from gene-dosage predictions. In order to ask whether $I_{A}$ in $S h$ heterozygotes followed a simple gene-dosage effect, it was necessary to obtain an expected value for heterozygous $I_{A}$. 


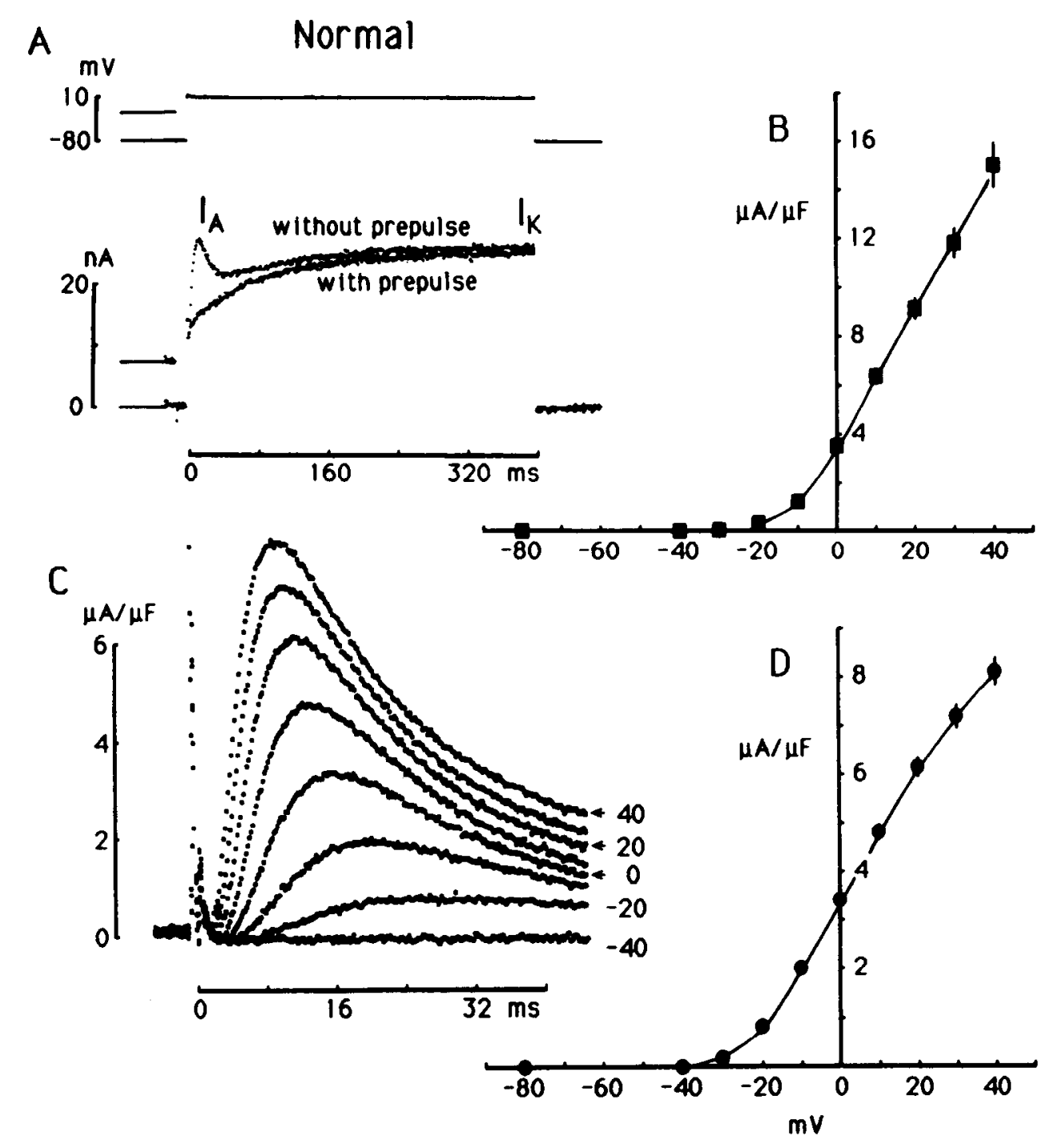

Figure 1. Physiological separation of membrane currents in normal larval muscle at $4^{\circ} \mathrm{C}$. Inward currents and $\mathrm{Ca}^{2+}$-dependent outward currents were abolished by the use of $\mathrm{Ca}^{2+}$-free saline in this and all subsequent figures. $A$, Two superimposed traces of total membrane currents (lower part) elicited by voltage steps (upper part) from a holding potential $\left(V_{\mathrm{H}}\right)$ of $-80 \mathrm{mV}$. Upward deflections indicate outward currents or depolarizations. The depolarization elicited an early outward current, $I_{A}$, and a delayed but sustained current, $I_{K}$. When a 2-sec prepulse to $-20 \mathrm{mV}$ preceded the voltage step, $I_{A}$ was inactivated and only $I_{K}$ was observed (see Materials and Methods). $B$, Currentvoltage $(I-V)$ relation for $I_{K}$ pooled from 15 fibers. After linear subtraction of leakage currents and adjustment for fiber surface area, the active outward current density (mean \pm SEM) is plotted against membrane potential. All measurements were made from paradigms like that shown in $A$ with the noninactivating current measured at the end of the voltage step being defined $\mathrm{I}_{\mathrm{K}}$. $C$, Superimposed traces of inactivating current (determined by subtraction of corresponding traces in $A$ ) elicited from $V_{\mathrm{H}}$ $=-80 \mathrm{mV}$. Each trace represents the mean current density ( 15 fibers) elicited by voltage steps to the indicated potentials. This current is predominantly $I_{A}$ in physiological isolation from $I_{K}$ (see text). $D, I-V$ relation for $\mathrm{I}_{\mathrm{A}}$ as defined in $C$. Each point represents the current density (mean \pm SEM) measured at the peak of $\mathrm{I}_{\mathrm{A}}$. Same fibers as in $B$ and $C$.

The sample size used in quantifying $\mathrm{I}_{\mathrm{A}}$ in homozygous $S h$ mutants was roughly uniform, as was the variance of the measured distributions of $I_{A}$ amplitudes (see Table 1). Therefore, to obtain an expected mean and variance for $I_{A}$ in $S h$ heterozygotes, the values for $I_{A}$ (mean \pm variance) measured in homozygous parents were simply averaged and weighing procedures for expected variances based on sample sizes were avoided. The observed and expected values were subjected to a Student's $t$-test at 0.01 and 0.001 levels of significance.

A similar test was made after normalizing the parental and offspring $I_{A}$ (mean \pm variance) to the amplitude of $I_{K}$. For each genotype, the mean $I_{A}$ was divided by the mean $I_{K}$ to give the $I_{A} / I_{K}$ ratio (cf. Tables 1 and 2). The variance of the ratio of $I_{A}$ and $I_{K}$ distributions was calculated according to Fieller (1932), assuming a correlation coefficient of zero between $I_{A}$ and $I_{K}$. The variance calculated with the latter assumption places an upper limit on the probable value and thus represents a conservative estimate.

\section{Results}

\section{Normal membrane currents}

Passive membrane properties. To ensure that the strains of different genotypes showed no general membrane defects, the passive membrane properties were determined in all (281) fibers in this study. The membrane capacitance, $c_{\mathrm{m}}$, resistance, $r_{\mathrm{m}}$, and time constant, $\tau_{m}$, were determined under voltage-clamp conditions in this subset of identified fibers (see Materials and Meth- ods). In normal female larvae the values for $r_{\mathrm{m}}, c_{\mathrm{m}}$, and $\tau_{\mathrm{m}}$ were $8.12 \pm 0.49 \mathrm{M} \Omega, 4.05 \pm 0.28 \mathrm{nF}$, and $31.9 \pm 1.99 \mathrm{msec}$ (mean $\pm \mathrm{SEM}, n=15$ ), respectively. Similar values were observed in male larvae (Table 2). Measurements of $c_{\mathrm{m}}$ and $r_{\mathrm{m}}$ indicated that the fibers of different genotypes were comparable in surface area. Furthermore, of the 30 mutant (homozygous and heterozygous) genotypes analyzed, 28 had $\tau_{\mathrm{m}}$ that were not significantly different from normal. The differences shown in the remaining 2 genotypes $\left(S h^{5} / S h^{r k 1020}\right.$ and $S h^{E 62} / S h^{102}$ ), although resolved by the Student's $t$-test, were all within $37 \%$ of normal. (For details of the measurements see Haugland, 1987.)

Since quantitative conclusions of gene-dosage effects on membrane currents rely on precise determination of current density, the density was obtained by adjusting the active current amplitude to $c_{\mathrm{m}}$, which is thought to be proportional to the membrane area under voltage clamp. This eliminated the variations due to different fiber sizes or uncertainty in estimation of membrane area by microscopic measurements (Wu and Haugland, 1985). Current density, in the units of $\mu \mathrm{A} / \mu \mathrm{F}$, was used in all current-voltage $(I-V)$ relations throughout this study.

Physiological separation of outward currents. In previous studies, the analysis of $\mathrm{I}_{\mathrm{A}}$ amplitude and kinetics in larval muscles was limited by the overlap of $I_{A}$ and $I_{K}$ activation over a broad 

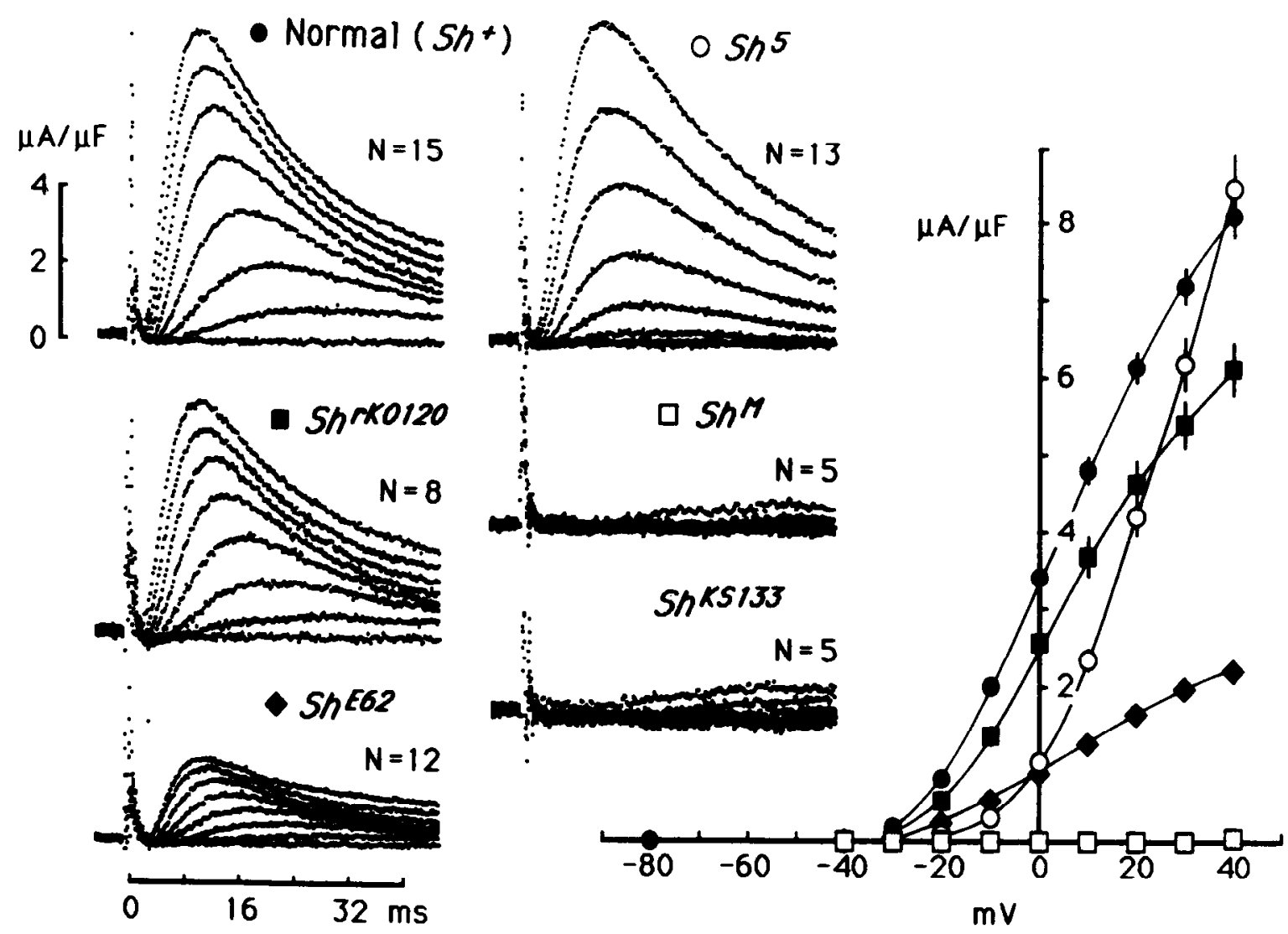

Figure 2. $\quad I_{A}$ in normal and $S h$ female larval muscle. The voltage dependence of the peak $I_{A}$ for each family of traces (elicited by the same sequence of voltage steps as in Fig. $1 C$ ) is indicated in the $I-V$ relation. In this and all subsequent figures, traces represent the mean current density from the number of fibers indicated in Tables 1 and 2 for each particular genotype. The mean and SEM of peak $I_{A}$ from the same measurements are shown in the $I-V$ relations. In $S h^{r \kappa O I 20}$ and $S h^{E 62}$ muscle, $I_{\mathrm{A}}$ is reduced to about $78 \%$ and $28 \%$ of normal, respectively. $\mathrm{I}_{\mathrm{A}}$ in $S h^{K S I 33}$ and $S h^{M}$ is eliminated. In $S h^{5}$ muscle, the voltage dependence of $\mathrm{I}_{\mathrm{A}}$ is shifted to more positive potentials and steepened.

range of potentials (Wu et al., 1983; Wu and Haugland, 1985). The present study circumvented these limitations by utilizing differences in inactivation properties between $I_{A}$ and $I_{K}$ to achieve a nearly complete separation of these currents. The fraction of inactivating $\mathrm{I}_{\mathrm{A}}$ extracted by our pulse paradigm (Fig. $1 A$ ) was determined by comparing the normal data (with and without the prepulse) with data from $S h$ mutations ( $S h^{M}$ and $S h^{K S 133}$ ) that completely eliminated $\mathrm{I}_{\mathrm{A}}$. These comparisons indicated that the prepulse inactivated about $86 \%$ of $\mathrm{I}_{\mathrm{A}}$ in normal muscles.

The voltage dependence of the delayed potassium current, $I_{K}$, determined at the end of the test pulse and adjusted for linear leakage currents, is plotted in Figure $1 B$. This current was first detectable near $-20 \mathrm{mV}$, slowly reaching a plateau after 400 $\mathrm{msec}$, and became larger and rose more rapidly to a steady state in $150 \mathrm{msec}$ with stronger depolarizations (cf. Wu and Haugland, 1985).

Figure $1 C$ shows a family of $I_{A}$ elicited by different depolarizing voltage steps. Both the amplitude and kinetics of $\mathrm{I}_{\mathrm{A}}$ were voltage dependent. Normal $I_{A}$ was first detectable at $-30 \mathrm{mV}$ and rose slowly to a peak after $25 \mathrm{msec}$. With stronger depolarizations, $I_{A}$ became larger and faster; the time to peak was near $10 \mathrm{msec}$ at $+40 \mathrm{mV}$. The $I-V$ relation at the time of peak $I_{A}$ is shown in Figure $1 D$.

\section{Altered $I_{A}$ in homozygous Sh mutants}

With the same protocol (Fig. 1), $\mathrm{I}_{\mathrm{A}}$ obtained from 5 mutants is compared with normal in Figure 2. The most common phenotype was the complete elimination of $\mathrm{I}_{\mathrm{A}}$, as seen in $S h^{K S 133}$ and $S h^{M}$ fibers. Two other mutations, $S h^{102}$ and $S h^{K 82 a}$, also completely eliminated $\mathrm{I}_{\mathrm{A}}$ (see Table 1 ). The residual current in

Table 2. Passive and active properties of larval muscles in normal and aneuploid $S h$ male larvae

\begin{tabular}{lllll} 
Genotype & $S h^{+} / \mathrm{Y}$ & $S h^{M} / \mathrm{Y} ; S h^{+}$ & $S h^{K S 133} / \mathrm{Y} ; S h^{+} S h^{+} / \mathrm{Y} ; S h^{+}$ \\
\hline$n$ & 5 & 4 & 8 & 5 \\
$r_{\mathrm{m}}(\mathrm{M} \Omega)$ & $8.58 \pm 1.11$ & $6.12 \pm 0.78$ & $7.48 \pm 0.75$ & $7.39 \pm 0.84$ \\
$\mathcal{C}_{\mathrm{m}}(\mathrm{nF})$ & $3.51 \pm 0.19$ & $4.40 \pm 0.58$ & $3.95 \pm 0.33$ & $3.39 \pm 0.17$ \\
$\tau_{\mathrm{m}}(\mathrm{msec})$ & $29.8 \pm 3.71$ & $26.2 \pm 3.73$ & $29.8 \pm 2.42$ & $25.1 \pm 1.89$ \\
$\mathrm{I}_{\mathrm{A}}(\mu \mathrm{A} / \mu \mathrm{F})$ & $4.17 \pm 0.33$ & $4.38 \pm 0.49$ & $1.13 \pm 0.16^{b}$ & $8.96 \pm 1.25^{b}$ \\
$\mathrm{I}_{\mathrm{K}}(\mu \mathrm{A} / \mu \mathrm{F})$ & $6.22 \pm 0.79$ & $7.66 \pm 0.44$ & $7.75 \pm 0.53$ & $8.01 \pm 0.71$ \\
$\mathrm{I}_{\mathrm{A}} / \mathrm{I}_{\mathrm{K}}$ & $0.67 \pm 0.10$ & $0.57 \pm 0.07$ & $0.14 \pm 0.02^{a}$ & $1.12 \pm 0.19^{a}$
\end{tabular}

The mean and SEM are shown, $n$, Number of fibers examined.

${ }^{a} p<0.01$.

${ }^{b} p<0.001$. 

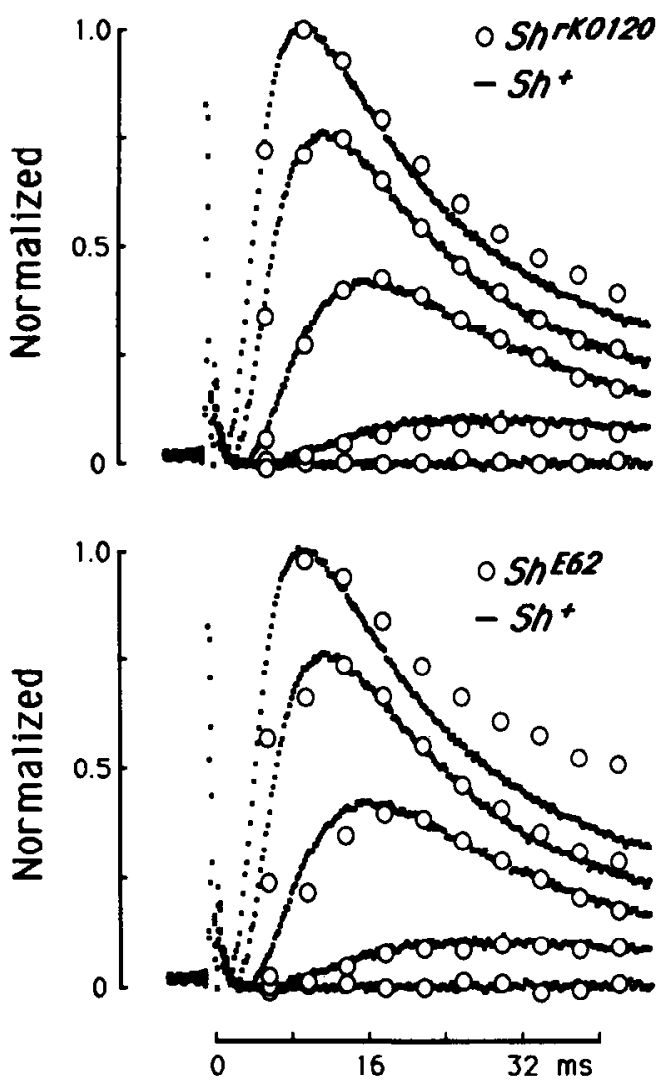

Figure 3. Comparison of the time course and voltage dependence of $\mathrm{I}_{\mathrm{A}}$ in $S h^{r K 0 / 20}$ and $S h^{t 62}$ with normal. In this and all following figures (except Fig. $11 B$ ), traces represent currents clicitcd by voltage steps to $-40,-20,0,+20$, and $+40 \mathrm{mV}$. Following normalization, $I_{A}$ in $S h^{r K 0120}$ (upper, open circles) and $S h^{E 62}$ (lower, open circles) muscle are superimposed on normal (traces). In these mutants, $\mathrm{I}_{\mathrm{A}}$ is simply reduced. Same data as in Figure 2.

$S h^{M}$ and $S h^{K S 133}$ became significant only above $+20 \mathrm{mV}$ and can be attributed to inactivating $\mathrm{I}_{\mathrm{K}}$ extracted by the pulse protocol (less than $5 \%$ of the total $\mathrm{I}_{\mathrm{K}}$ ). These currents rose slowly with a time course and $I-V$ relation resembling that of $I_{K}$ (data not shown). Similar current was also observed in normal muscles treated with 4-aminopyridine (4-AP) at concentrations sufficient to completely block normal $I_{A}$.

In 2 other mutants, $I_{\mathrm{A}}$ was reduced. The $S h^{r k 0120}$ mutation reduces $\mathrm{I}_{\mathrm{A}}$ to about $78 \%$ of normal (Fig. 2 and Table 1). In $S h^{E 62}$ muscle the reduction was more striking, to only $28 \%$ of normal. The residual current in these 2 mutants was normalized with a single normalization factor (based on the $I_{A}$ evoked at $+30 \mathrm{mV}$ ) and superimposed on normal. As would be expected from a simple reduction in current density, the resulting amplitude and time course were nearly identical (Fig. 3). These mutations are thus hypomorphic, exhibiting a reduced, but otherwise normal, current.

Inspection of the normalized mutant data (open circles in Fig. 3) does suggest an excess of outward current at late time during the most positive voltage steps. The discrepancies at these potentials may be attributed to the disproportional magnification of residual, inactivating $I_{K}$. This interpretation is supported by the finding that the discrepancy was more pronounced in the genotype (e.g., $S h^{E 62}$ ) with the smaller residual current.

In contrast, the $S h^{5}$ mutation caused alterations that could not be described as a simple reduction in current density. At potentials between -30 and $+20 \mathrm{mV}, S h^{5} I_{A}$ was either absent or reduced. Depolarizations to $+40 \mathrm{mV}$ did, however, elicit a large $I_{A}$ of nearly normal amplitude (see traces, Fig. 2). The $I-$ $V$ relation for this current was thus shifted to more positive potentials and steepened (Fig. 2). Furthermore, $S h^{5} I_{A}$ followed a slightly slower time course as compared to normal (see Haugland, 1987, for details). In sum, these changes in the $I-V$ relation and kinetics of $\mathrm{I}_{\mathrm{A}}$ in $S h^{5}$ fibers most likely reflected altered properties of the $I_{A}$ channel.

As was done for normal $I_{A}$ (see above), the fraction of inactivating $\mathrm{I}_{\mathrm{A}}$ in $S h^{\text {rKOI20 }} S h^{E 62}$, and $S h^{5}$ was determined by comparing data with those from $S h$ mutations that eliminated $I_{A}$. The prepulse inactivated about $78 \%, 90 \%$, and $74 \%$ of $\mathrm{I}_{\mathrm{A}}$ in $S h^{r K O 120}, S h^{E 62}$, and $S h^{5}$, respectively.

The delayed outward current, $I_{K}$, was analyzed using the same pulse paradigm as in Figure $1 A$ (data not shown). The results confirmed our previous report (Wu and Haugland, 1985) that these $S h$ mutations do not affect the amplitude or kinetics of $\mathbf{I}_{\mathbf{K}}$.

\section{Altered $I_{A}$ in heterozygotes and aneuploids}

Complementation tests among null alleles. The analysis of $\mathrm{I}_{\mathrm{A}}$ in heterozygous combinations of the $S h$ mutations provided an opportunity to determine whether these mutations affect the same or different gene products in the $\mathrm{I}_{\mathrm{A}}$ channel. We first examined whether heterozygous combinations of the $4 S h$ mutations that eliminate $\mathrm{I}_{\mathrm{A}}$ would result in detectable $\mathrm{I}_{\mathrm{A}}$. We constructed all possible combinations involving $S h^{M}\left(S h^{K S / 33} / S h^{M}\right.$, $S h^{102} / S h^{M}$, and $\left.S h^{K 82 a} / S h^{M}\right)$. In muscles of such genotypes $\mathrm{I}_{\mathrm{A}}$ was not observed, indicating that these 4 mutations do not complement (Table 1, see Haugland, 1987, for details).

$\mathrm{Sh}^{\mathrm{M}}$ and $\mathrm{Sh}^{\mathrm{K} 82 \mathrm{a}}$ behave as deficiencies. Although similar in phenotypc, the above 4 null mutations may be categorized genetically into 2 distinct classes. One class of null mutations behaves as a simple deficiency. With an absence of gene product or production of inert, nonfunctional product, these mutations are amorphic, exhibiting no ability to affect the function of other mutations. The second class of null mutations may give rise to an abnormal gene product, which exhibits a novel, unexpected dominance when combined with other gene products in multimeric functional assembly.

Both cases were observed when we examined $I_{A}$ in various combinations of null $S h$ mutations with other $S h$ mutations. In all combinations of $S h^{+}, S h^{r K 0120}, S h^{E 62}$, and $S h^{5}$ with $S h^{M}, I_{\mathrm{A}}$ appeared to follow a simple gene-dosage effect; the resulting current was always about the average of the 2 currents observed in the homozygotes (Fig. 4). Even the shifted and steepened voltage dependence of $S h^{5} \mathrm{I}_{\mathrm{A}}$ was expressed according to gene dosage in the $S h^{5} / S h^{M}$ heterozygotes (Fig. $4 B$ ), as though the remaining currents were contributed solely by the $S h^{5}$ chromosome. The adherence of $I_{A}$ to a simple gene-dosage effect suggests that the $S h^{M}$ allele behaves in a fashion indistinguishable from a simple deficiency (an amorph), neither enhancing nor suppressing the function of the other alleles.

A further test for an amorphic mutation is to determine whether the presence of a duplication of the normal locus restores the wild-type phenotype. We examined $\mathrm{I}_{\mathrm{A}}$ in $S h^{M}$ aneuploid male larvae possessing an additional copy of the $S h^{+}$locus on the third chromosome (by using the translocation $D p(1 ; 3) J C 153$; see Materials and Methods). In Drosophila, expression of sexlinked genes, such as $S h$, is dosage-compensated. Male flies 

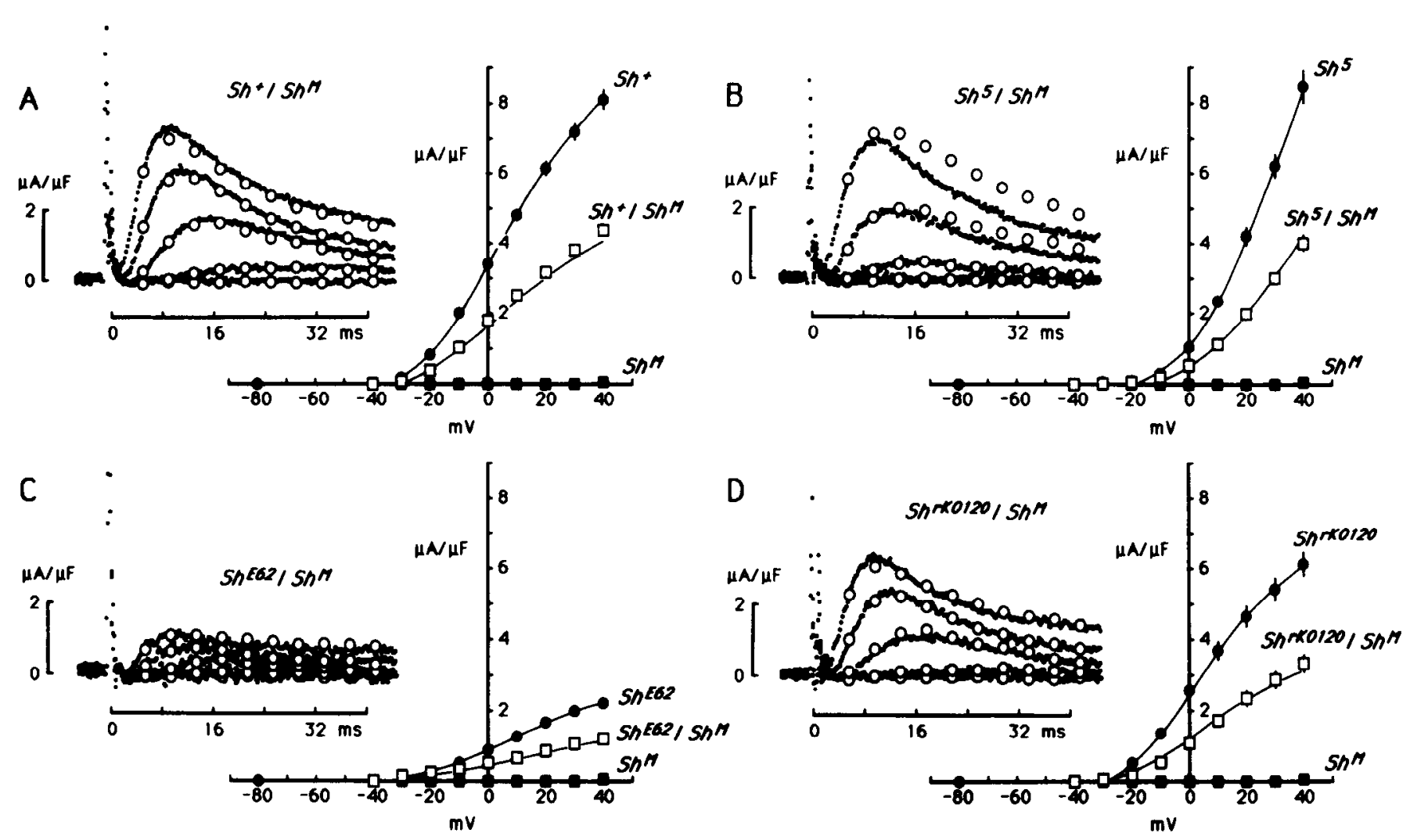

Figure 4. Comparison of $\mathrm{I}_{\mathrm{A}}$ observed in $S h^{M}$ heterozygotes with that expected from gene dosage. $A, \mathrm{I}_{\mathrm{A}}$ in $S h^{+} / S h^{M}$ muscle (traces) is superimposable on the average of the $S h^{+}$and $S h^{M}$ currents (open circles, from same data as in Fig. 2). The graph represents the $I-V$ relation of peak $I_{A}$ in normal, $S h^{+} / S h^{M}$, and $S h^{M}$ muscles. The upper continuous curve was fit by eye to the $S h^{+}$data while the lower continuous curve represents the peak $I_{A}$ predicted from gene dosage. In $S h^{+} / S h^{M s}$ muscle, $\mathrm{I}_{\mathrm{A}}$ is reduced to about $50 \%$ of normal. $B-D$, Similarly, $\mathrm{I}_{\mathrm{A}}$ in $S h^{s} / S h^{M}, S h^{E 62} / S h^{M}$, and $S h^{r \kappa o 120} / S h^{M}$ heterozygotes is near that expected from gene dosage.

possess only a single copy of the $\mathrm{X}$ chromosome, as opposed to 2 copies in females. Each $X$ chromosome in females contributes equally to the synthesis of gene products while the single $\mathrm{X}$ chromosome in males synthesizes as much as the 2 female $X$ chromosomes combined. Adult aneuploid male flies of this genotype were behaviorally normal and did not exhibit the legshaking behavior characteristic of the $S h$ mutants. In larval muscle fibers of these aneuploids, the density of $I_{K}$ and passive membrane properties were not different from normal (Table 2).
Most significantly, as shown in Figure 5 they possessed an $I_{A}$ nearly identical to that observed in the controls, $S h^{+}$males (see also Table 2).

We have examined another mutation, $S h^{\kappa 82 a}$, which gave results similar to that described for $S h^{M}$. Heterozygous combinations of $S h^{K 82 a}$ with $S h^{+}, S h^{\text {KOIzo }} S h^{E 62}$, and $S h^{5}$ also followed a simple gene-dosage effect (Table 1). Thus, the $S h^{\kappa 8 z a}$ allele also appears to be amorphic, with the current in heterozygotes reflecting the synthetic capacity of the other allele.
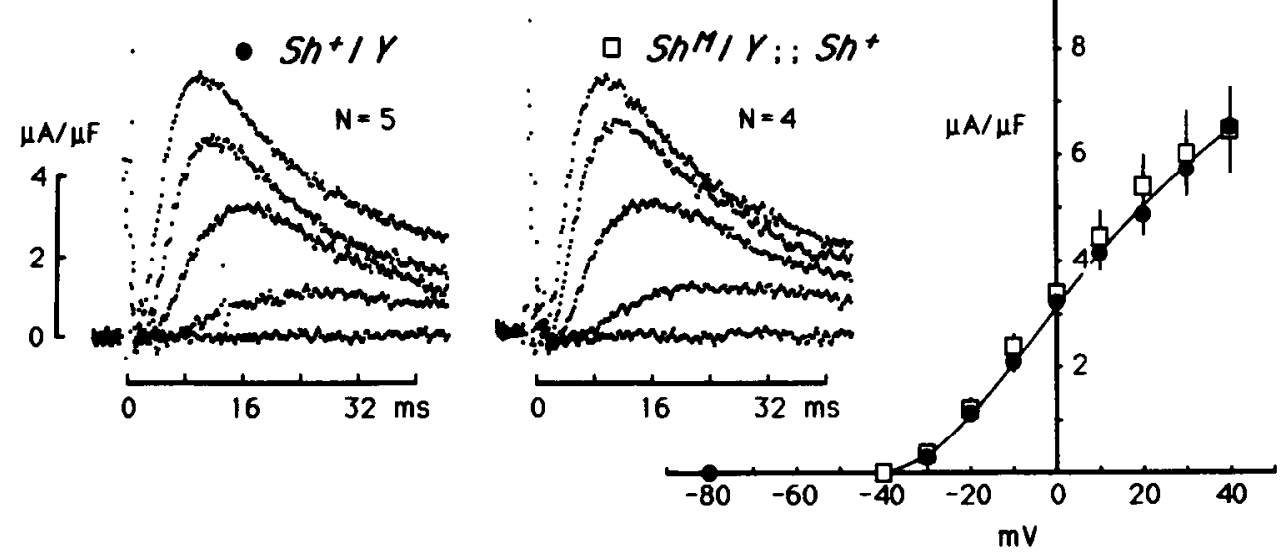

Figure 5. $\mathrm{I}_{\mathrm{A}}$ in a $S h^{M}$ male larva possessing a duplication of $S h^{+}$on the third chromosome is near normal. The continuous curve was fit by eye to the normal data and also represents the prediction from gene dosage. 

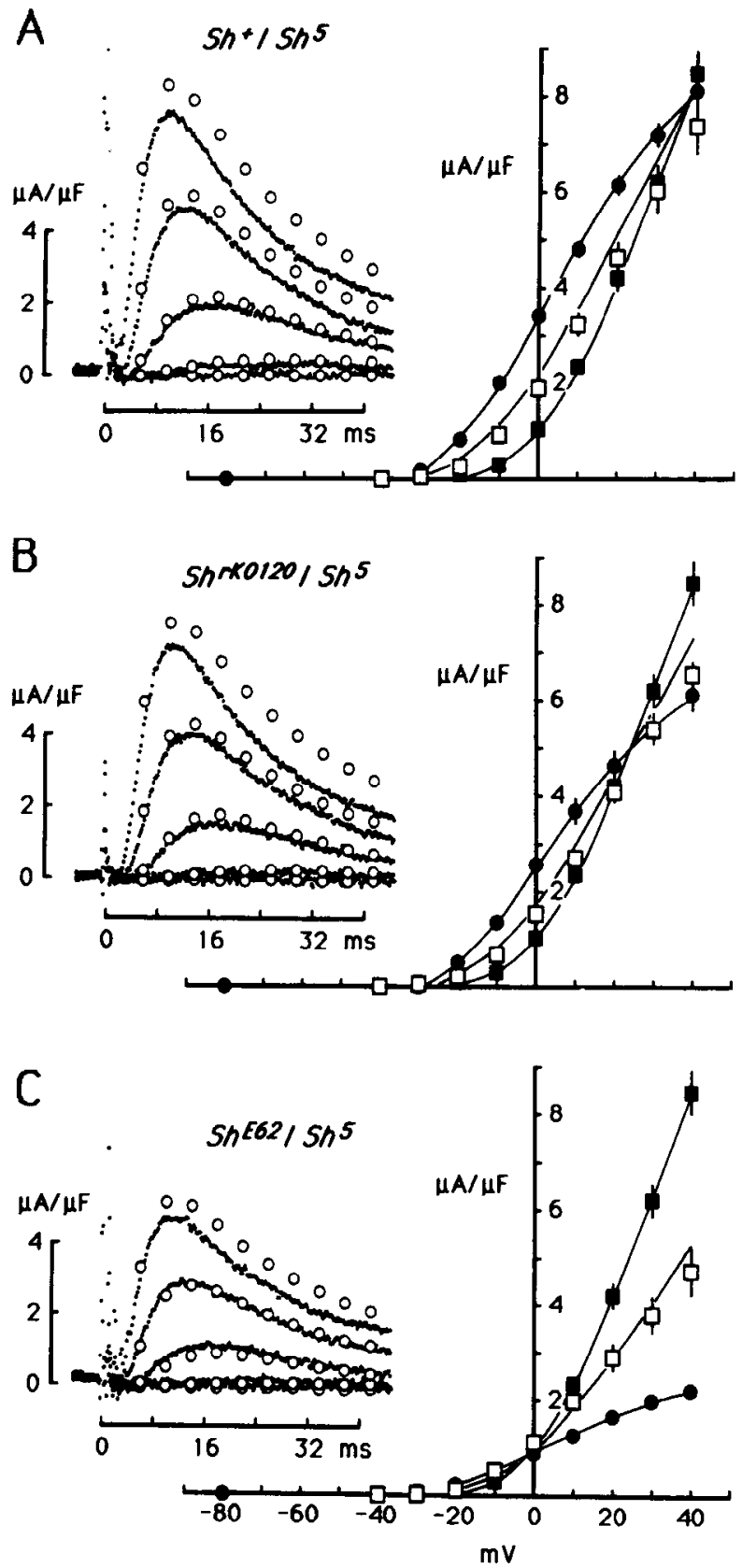

Figure 6. Comparison of $\mathrm{I}_{A}$ observed in $S h^{5}$ heterozygotes with that expected from gene dosage. $A, \mathrm{I}_{\mathrm{A}}$ in $S h^{+} / S h^{5}$ muscle (traces) is superimposable on the average of the $S h^{+}$and $S h^{5}$ currents (open circles, from same data as in Fig. 2). The graph represents the $I-V$ relation of peak $\mathrm{I}_{\mathrm{A}}$ in normal (filled circles), $S h^{+} / S h^{5}$ (open squares), and $S h^{5}$ (filled squares) muscle. The upper and lower continuous curves were fit by eye to the normal and $S h^{5}$ data while the middle curve represents the average of the 2 curves and is peak $\mathrm{I}_{\mathrm{A}}$ predicted from gene dosage. In $S h^{+} S h^{5}$ muscle, $I_{A}$ exhibits a voltage dependence intermediate between that of normal and $S h^{5}$. B and $C$, Similarly, $\mathrm{I}_{\mathrm{A}}$ in $S h^{r K 0120} / S h^{5}, S h^{E 62} / S h^{5}$ heterozygotes is near that expected from gene dosage.

Complementation tests among leaky alleles. A different set of experiments examined $I_{A}$ in all possible heterozygotic combinations among $S h^{+}, S h^{5}, S h^{r K 0120}$, and $S h^{E 62}$. The $\mathrm{I}_{\mathrm{A}}$ observed in $S h^{+} / S h^{5}$ heterozygotes (traces in Fig. $6 \mathrm{~A}$ ) is compared with that expected from gene dosage (open circles in Fig. $6 A$ ). The peak $\mathrm{I}_{\mathrm{A}}$ in $S h^{+} / S h^{5}$ muscle exhibited an $I-V$ relation (Fig. $6 A$ ) inter-
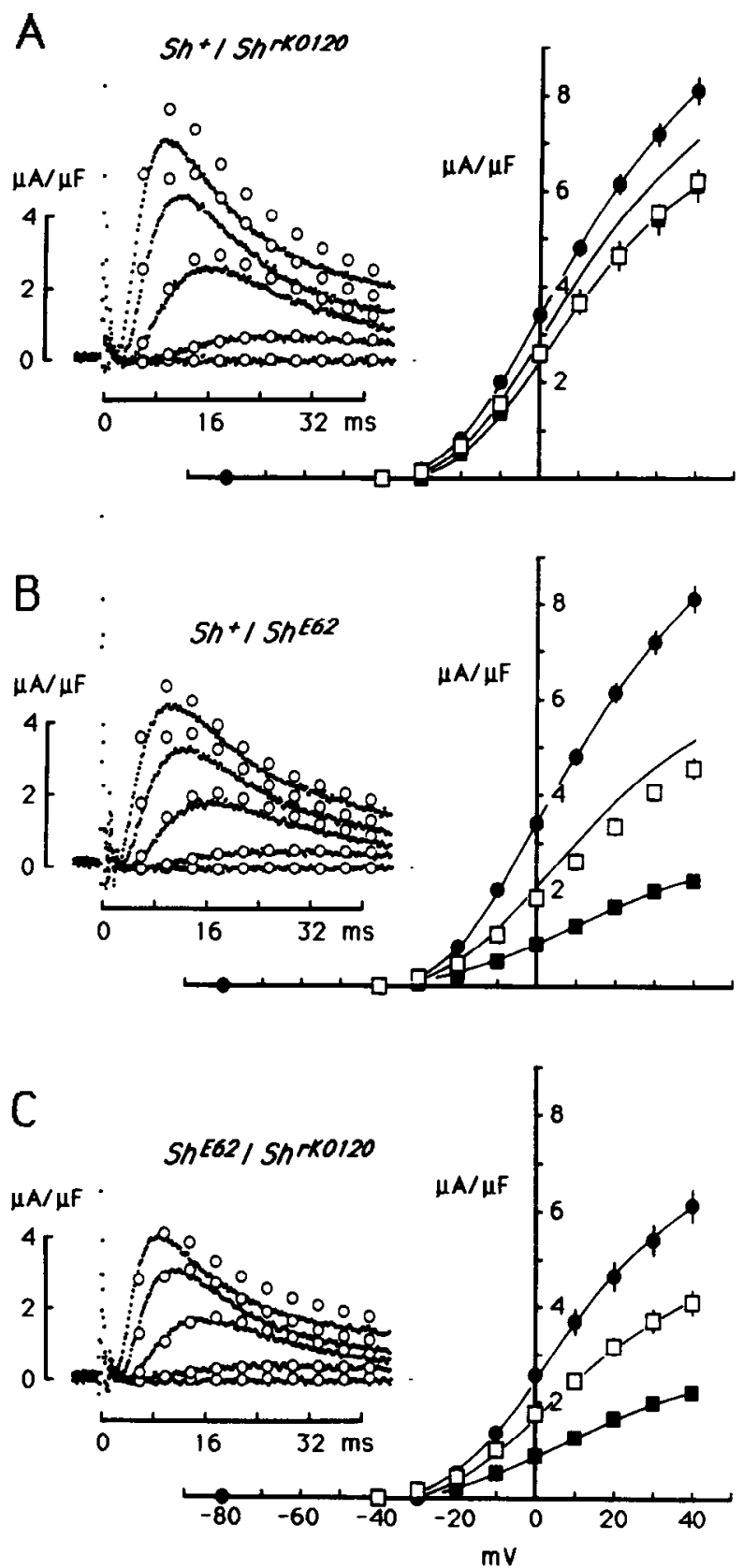

Figure 7. $\quad \mathrm{I}_{\mathrm{A}}$ in heterozygotic combinations of $S h^{+}, S h^{r \kappa 0 / 20}$, and $S h^{E 62}$ is compared with that expected from gene dosage (cf. Fig. 6 legend for details regarding the $I-V$ relations).

mediate between those of $S h^{+}$and $S h^{5}$ homozygous muscles. This is consistent with the prediction that the $\mathrm{I}_{\mathrm{A}}$ channels in the heterozygotes consist of 2 equal populations of normal and $S h^{5}$ channels.

Also shown are 2 other parallel experiments that compared the $\mathrm{I}_{\mathrm{A}}$ observed in $S h^{r K O I 20} / S h^{5}$ and $S h^{E 62} / S h^{5}$ muscles with that expected from gene dosage (Fig. $6, B, C$ ). In both examples, the observed current was intermediate from that observed in the homozygous muscles, in close agreement with the prediction that the total $I_{A}$ is composed of $50 \%$ of the $S h^{5}$ type and $50 \%$ of the other type. In neither case was the observed current significantly different from that predicted (Table 1). 
$5 h+12 h \times 5133$

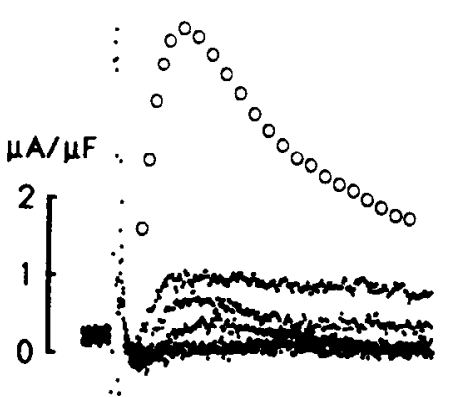

$S h r \times 0120 / \operatorname{Sh} \times S 133$

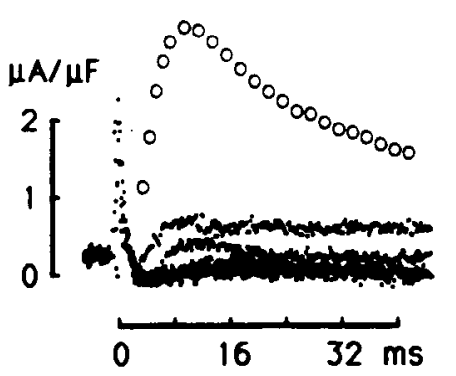

$\operatorname{Sh} 5 / \sin \times 5 / 33$
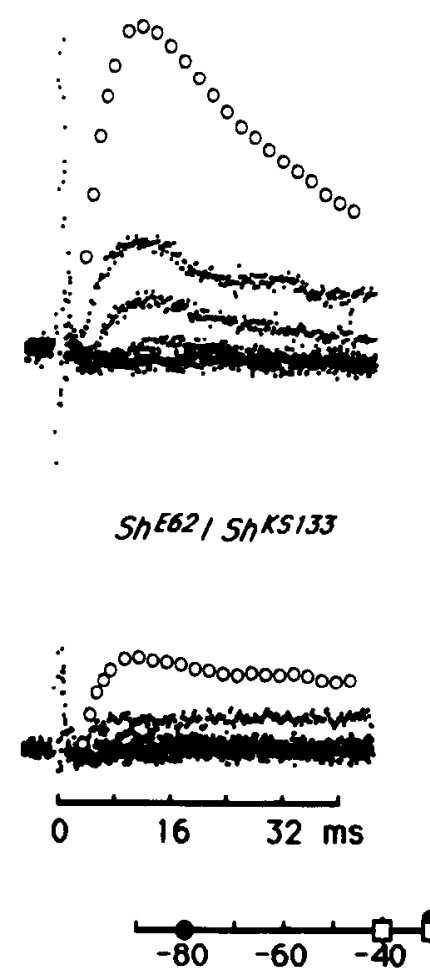
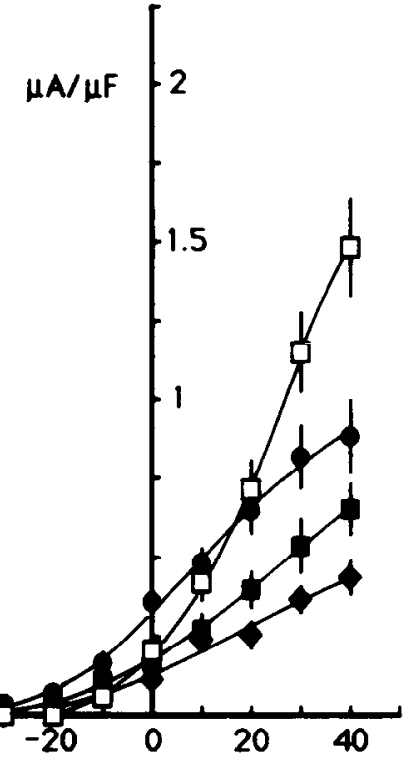

Figure 8. $\quad \mathrm{I}_{\mathrm{A}}$ in $S h^{\mathrm{KSI33}}$ heterozygotes. The traces represent $I_{A}$ in the indicated $S h^{K S 133}$ heterozygotes evoked by voltage steps from $-80 \mathrm{mV}$ to $-40,-20,0$, +20 , and $+40 \mathrm{mV}$. The open circles indicate the $I_{A}$ at $+40 \mathrm{mV}$ predicted from gene dosage. The graph represents the $I-V$ relation of peak $I_{\mathrm{A}}$ in $S h^{+} / S h^{K S I 33}$ (filled circles), $S h^{\mathrm{K} K \mathrm{~L} / 20} / \mathrm{Sh}^{\mathrm{KS} / 33}$ (filled squares), $S h^{E 62} / S h^{K S 133}$ (filled diamonds), and $S h^{5} / S h^{K S I 33}$ (open squares) muscles. In these muscles, $I_{A}$ is much less than expected from gene dosage (see also Table 1). Nevertheless, the voltage dependence of the peak $I_{A}$ in $S h^{5} / S h^{K S 133}$ is characteristic of that in $S h^{5}$ whereas peak $I_{A}$ in the other heterozygotes is simply reduced but otherwise not different from normal.
Figure 7 shows experiments of the remaining 3 combinations, $S h^{+} / S h^{r K 0120}, S h^{+} / S h^{E 6 z}$, and $S h^{r K 0120} / S h^{E 6 z}$. In $S h^{r K 0120} / S h^{E 62}$ the observed $\mathrm{I}_{\mathrm{A}}$ was nearly identical to the expected value (Fig. $7 \mathrm{C}$ ). In $S h^{+} / S h^{r \kappa(n)}$ and $S h^{+} / S h^{F \kappa 2}$ fibcrs (Fig. $7, A, B$ ), $\mathrm{I}_{\mathrm{A}}$ showed a small shortage from the expected value at more positive potentials (see also Table 1); in $S h^{+} / S h^{r K O I 20}$ the difference was statistically significant (Table 1). Since the latter discrepancy is small (within $15 \%$ of the expected value), it probably does not indicate a violation of the gene-dosage effect but, rather, reflects a fluctuation due to small sample size. In sum, adherence of $I_{A}$ to a simple gene-dosage effect in heterozygotic combinations among $S h^{5}, S h^{r K O 120}, S h^{E 62}, S h^{M}$, and $S h^{K 82 a}$ suggests that these mutations are allelic, affecting a transcript coding for a structural component of the $I_{A}$ channel.

$\mathrm{Sh}^{\mathrm{KS} 133}$ and $\mathrm{Sh}^{102}$ are dominant null $\mathrm{Sh}$ mutations. In contrast to $S h^{M}$ and $S h^{K 82 a}$, the other 2 null mutations, $S h^{K S 133}$ and $S h^{102}$, produced dramatic departures from the gene-dosage effect in heterozygotes (see Table 1). Figure 8 shows the results obtained in various combinations of $S h^{+}, S h^{r K O 120}, S h^{E 62}$, and $S h^{5}$ with $S h^{K S / 33}$. In all cases the observed current (traces) was far below that predicted from a simple gene-dosage dependence (open circles, which show the expected current at $+40 \mathrm{mV}$ ). The traces in Figure 9 show the $\mathrm{I}_{\mathrm{A}}$ measured in all combinations of $S h^{+}$, $S h^{r K O I 20}, S h^{E 62}$, and $S h^{5}$ with $S h^{102}$. The observed currents were consistently less than expected (Fig. 9, open circles, which show the predicted values at $+40 \mathrm{mV}$ ). The degree of departure from gene dosage varied in an allele-specific fashion, with $S h^{+} S h^{102}$ $\mathrm{I}_{\mathrm{A}}$ being $37 \%$ of normal while $S h^{E 62} / S h^{102} \mathrm{I}_{\mathrm{A}}$ was only $17 \%$ of that in $S h^{E 62}$ homozygotes (Table 1, comparisons at $+10 \mathrm{mV}$ ). In contrast to the amorphic phenotypes of $S h^{M}$ and $S h^{K 82 a}$, the
$S h^{102}$ and $S h^{K S / 33}$ mutant gene products appeared to interfere or interact with the product altered by the rest of the $S h$ mutations (see Discussion).

The dominant phenotype of $S h^{K S 133}$ was further demonstrated in male $S h^{\text {KSI33 }}$ flies possessing one duplicated copy of the $S h^{+}$ locus $(D p(1 ; 3) . J C 153)$. These flies do shake under ether anesthesia (Tanouye et al., 1981), but the tremor is less severe. The larval muscles of these aneuploids exhibited an $\mathrm{I}_{\mathrm{A}}$ that was only $25 \%$ of that measured in a normal male (Fig. 10 and Table 2), in marked contrast to the $100 \%$ restoration of normal $I_{A}$ observed in $S h^{M}$ males with the same duplication (Fig. 5).

\section{Sh gene products but not other factors limit $I_{A}$ density}

To explore the possibility that the $I_{A}$ channel in larval muscle consists of only the $S h$ products, we examined $S h^{+}$male larvae possessing an additional copy of the $S h^{+}$locus (the same duplication as in Figs. 5 and 10). As shown in Figure 11, the $I_{A}$ observed in muscles of these aneuploids was about twice that seen in normal male larvae, whereas the sizc of $I_{K}$ remained normal. Consequently, there was a striking increase in the ratio $I_{A} / I_{K}$ in fibers of these aneuploids (Table 2).

The result implies that the limiting factor determining $\mathrm{I}_{\mathrm{A}}$ density is the amount of $S h$ products but not other limited gene products or resources, consistent with the idea that the $S h$ locus codes for the entire $I_{A}$ channel. This is exactly what is expected from gene-dosage compensation experiments in male Drosophila; 1 copy and 2 copies of $\mathrm{X}$-linked structural genes produce $100 \%$ and $200 \%$ of the gene products, respectively (see review by Stewart and Merriam, 1980). 
Figure 9. $\mathrm{I}_{\mathrm{A}}$ in $S h^{102}$ heterozygotes. The traces represent $\mathrm{I}_{\mathrm{A}}$ in the indicated $S h^{\prime 02}$ heterozygotes evoked by voltage steps from $-80 \mathrm{mV}$ to $-40,-20,0,+20$, and $+40 \mathrm{mV}$. The open circles indicate the $\mathrm{I}_{\mathrm{A}}$ at $+40 \mathrm{mV}$ predicted from gene dosage. The graph represents the $I-V$ relation of peak $\mathrm{I}_{\mathrm{A}}$ in $S h^{+} / S h^{102}$ (filled circles), $S h^{r K 0120} / S^{102}$ (filled squares), $S h^{E 62} / S h^{\prime O 2}$ (filled diamonds), and $S h^{5 /}$ $S h^{\prime 02}$ (open squares) muscles. In these muscles, $I_{A}$ is less than expected from gene dosage (sce also Table 1). Nevertheless, the voltage dependence of the peak $I_{A}$ in $S h^{5} / S h^{102}$ is characteristic of that in $S h^{5}$ whereas peak $I_{A}$ in the other heterozygotes is simply reduced but otherwise not different from normal.
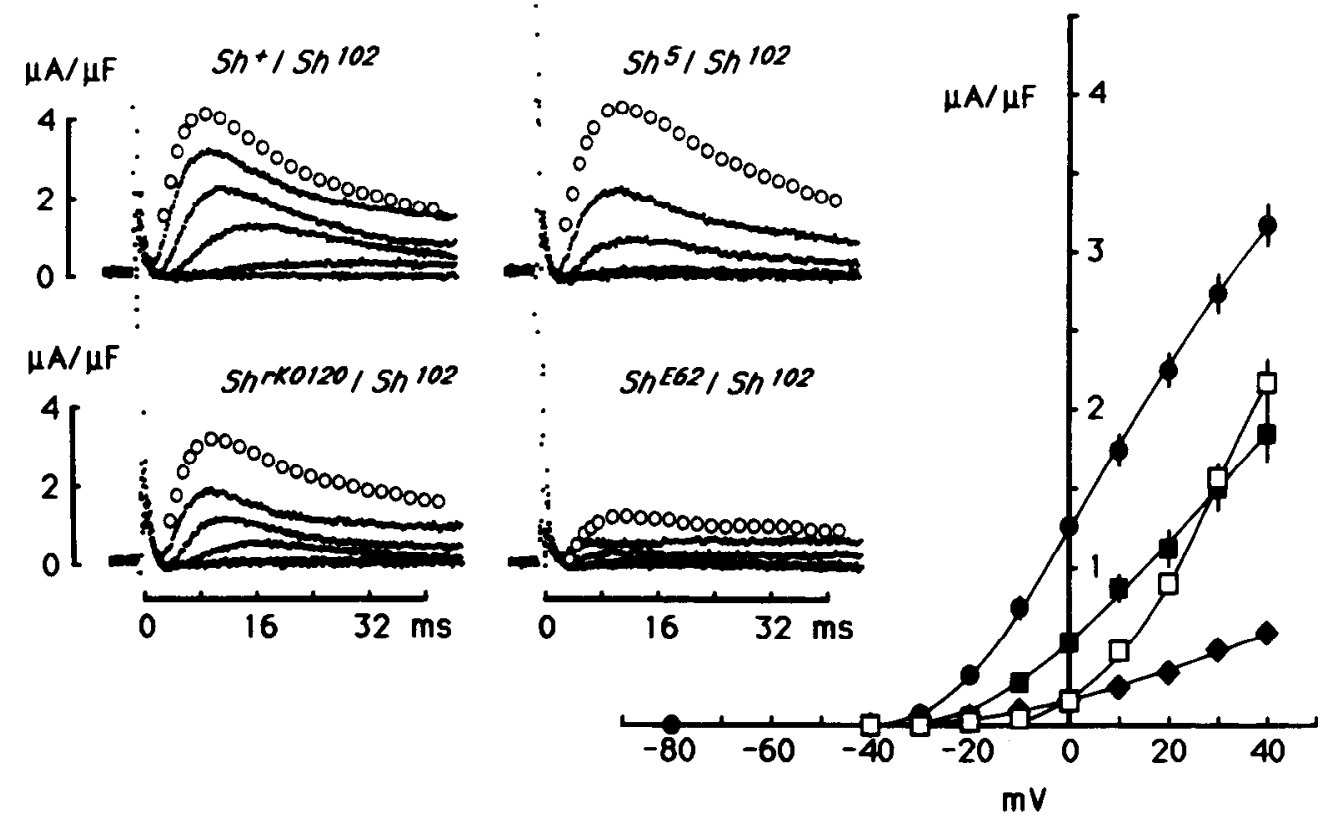

\section{Discussion}

This study demonstrated that the gene-dosage dependence of membrane channel proteins in Drosophila can be determined with precision by the voltage-clamp technique. A method of physiological separation of $I_{A}$ was used to quantify its amplitude and kinetics over a large range of membrane potentials. The results obtained from various heterozygous and aneuploid combinations of $S h$ mutants provide some information about the nature of the $S h$ mutations examined and the tissue-specific expression pattern of the $S h$ products. The interpretation of the data is also relevant to the questions of whether the $I_{A}$ channel contains multiple $S h$ proteins and of whether a homomeric or heteromeric arrangement is involved if the larval muscle channel consists of a subunit aggregate.

Does the Sh locus encode the entire $I_{A}$ channel?

The aneuploid males possessing an extra $S h$ locus $\left(S h^{+} / \mathrm{Y} ; ; S h^{+}\right)$ produce an $I_{A}$ that is 2-fold of that in normal males (Fig. 11).
Thus, the small translocated chromosome segment (cytological location 16E2-4;17A-B, Tanouye et al., 1981) containing the duplicated $S h$ locus appears to be fully capable of producing the normal amount of $I_{A}$ channels, consistent with the idea that the $S h$ locus codes for the entire structure of the $I_{A}$ channel.

This observation differs from the previous reports of the lack of gene-dosage effect in adult muscle fibers carrying duplicated copies of the $S h$ locus (Salkoff, 1983; Timpe and Jan, 1987; see below for details). Our result ensures that the number of functional $\mathrm{I}_{\mathrm{A}}$ channels is limited only by the amount of the $S h$ products but not by other resources, such as limited membrane sites or other channel subunits. Therefore, it is still possible that the $I_{A}$ channel contains a different subunit(s) that is produced in excess by a gene located in a region outside of the $S h$ locus, including the small flanking regions within the $D p(1 ; 3) J C 153$ segment.

Another conclusion that could be drawn from the results is that regulation of $I_{K}$ appears to be independent of the amount of $I_{A}$ present. Duplication of the $S h$ locus affects only the channel
Figure 10. $\mathrm{I}_{\mathrm{A}}$ in $S h^{\kappa S / 33}$ male larvae possessing a duplication of $S h^{+}$is near $25 \%$ of normal. The continuous line was fit by eye to the normal data and also represents the $I_{A}$ expected from gene dosage (contrast with Fig. 5).
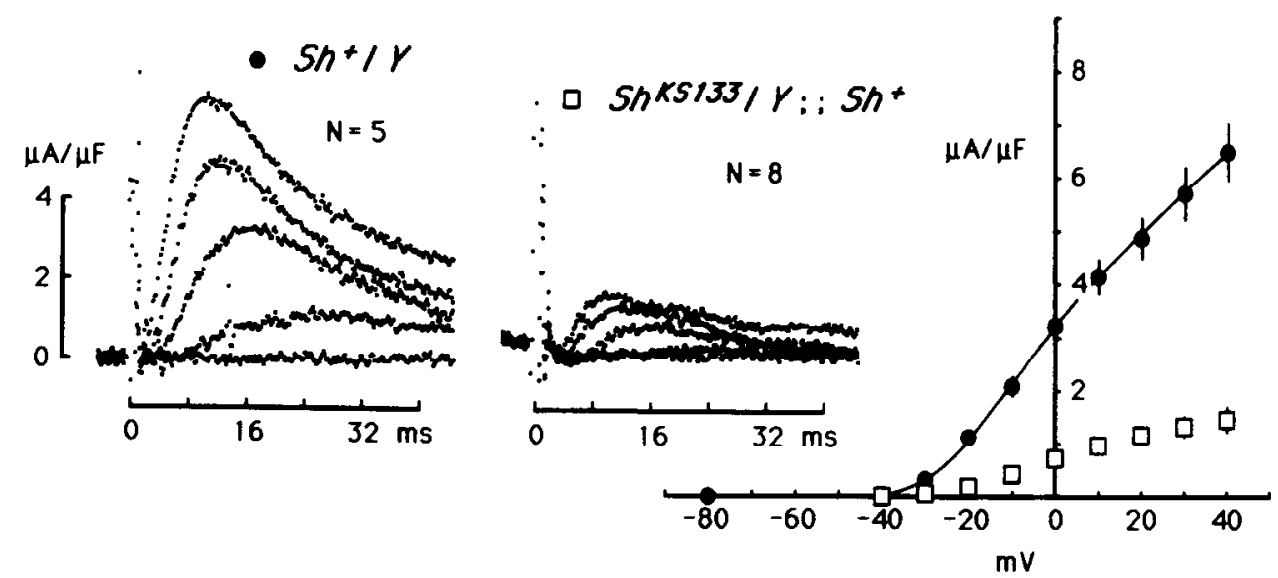
A
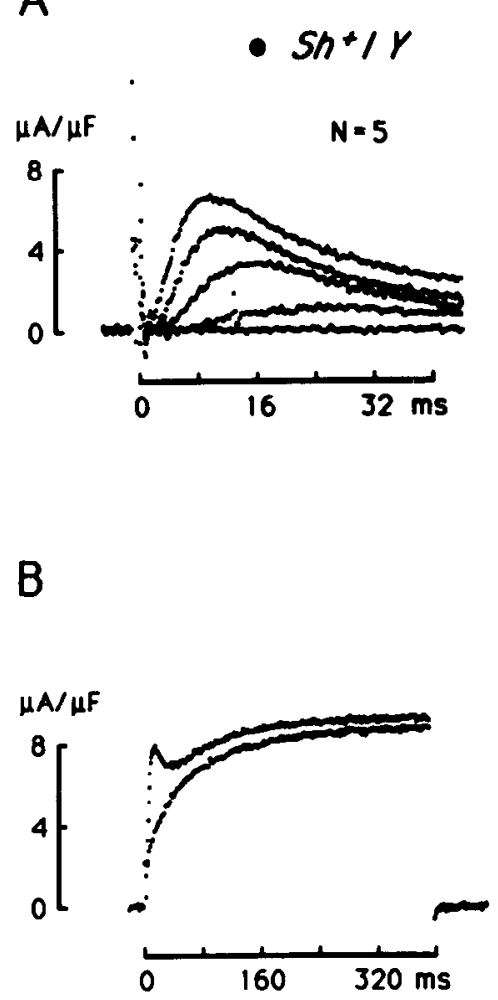
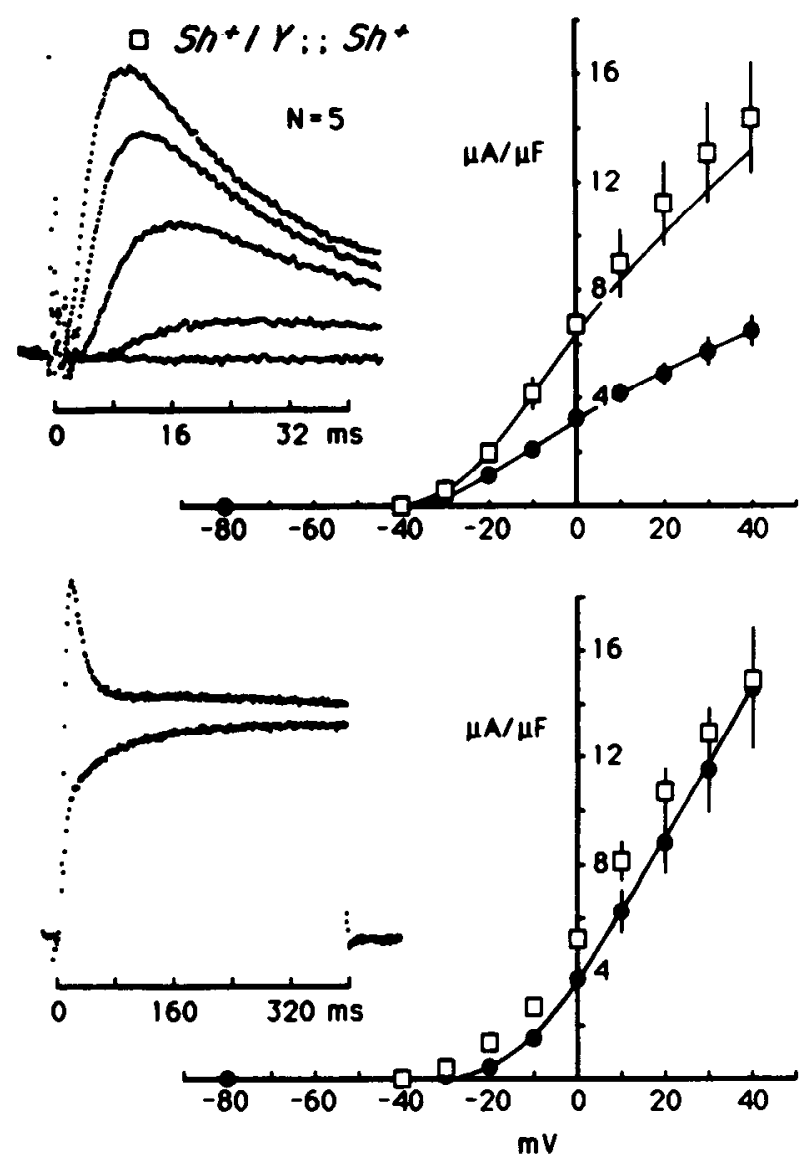

Figure 11. $\mathrm{I}_{\mathrm{A}}$ in $S h^{+}$male larvae possessing a duplication of $S h^{+}$is near twice that of normal but $\mathrm{I}_{\mathrm{K}}$ is near normal. 4 , The families of peak $\mathrm{I}_{\mathrm{A}}$ are shown and plotted in the $I-V$ relations. The lower continuous curve was drawn by eye to fit the normal data while the upper continuous curve represents the peak $\mathrm{I}_{\mathrm{A}}$ predicted from gene dosage. $B$, Two superimposed traces of membrane currents elicited by a voltage step to +20 $\mathrm{mV}$ with or without a prepulse (see Fig. $1 A$ for the pulse paradigm). The $S h^{+}$ duplication only increases the amplitude of $I_{\Lambda}$ whereas $I_{K}$ remains normal. The noninactivating $I_{K}$ measured at the end of the voltage step is plotted in the $I-V$ relations. A continuous curve is fit to the normal data and represents the expected $I_{K}$. density of $I_{A}$, but not $I_{K}$. Furthermore, in all homozygous, heterozygous, and aneuploid forms of $S h$ mutants examined, the density of $I_{K}$ was not up-regulated when $I_{A}$ was reduced or eliminated (Tables 1 and 2).

\section{The nature of the $\mathrm{Sh}$ mutations}

The functional alteration in $S h^{s}$ mutants is most likely related to altered structure of the $I_{A}$ channel. This is supported by our recent experiments in $S h^{5}$ larvae which revealed a striking increase in the sensitivity of $\mathrm{I}_{\mathrm{A}}$ to blockade by 4-AP concomitant with a change in channel gating properties (Haugland, 1987; Haugland and $\mathrm{Wu}, 1987)$.

The 2 amorphic alleles, $S h^{M}$ and $S h^{K 82 a}$, have been characterized molecularly. Both mutations affect the common regions that may interfere with multiple transcripts; $S h^{K 82 a}$ causes an inversion (Papazian et al., 1987) and $S h^{M}$ involves an insertion (Kamb et al., 1987). An altered production of $S h$ transcripts was reported in $S h^{\kappa 8 z a}$ flies (Schwarz et al., 1988). However, $S h^{M}$ may still produce a nonfunctional but inert translation product since polyclonal antibodies specific to a common region of the putative $S h$ proteins identify a protein species in immunoblots of $S h^{M}$ as well as $S h^{+}, S h^{5}$, and $S h^{K S / 33}$, but not of $S h$ deficiencies (Barbas et al., 1989).

The other 2 null mutations, $S h^{K S / 33}$ and $S h^{102}$, appear antimorphic, being dominant over their normal allele. These may be missense or nonsense mutations resulting in a gene product that interferes with other products in heterozygotes. Recent DNA sequence analysis and transformation experiments of $S h^{102}$ indicated truncated $S h$ products which interact with their normal counterpart in transformed flies carrying a normal dose of the wild-type $S h$ gene (Gisselmann et al., 1989).

The $S h^{r K O 220}$ and $S h^{E 62}$ mutations reduce the amplitude of $\mathrm{I}_{\mathrm{A}}$ without causing a detectable change in properties. This phenotype could be explained by a simple reduction in the number of functional $\mathrm{I}_{\mathrm{A}}$ channels, although a decreased channel conductance cannot be ruled out. Previous genetic experiments suggest that the $S h^{E 62}$ and $S h^{r K 0120}$ mutations may affect sites relatively distant (Tanouye et al., 1981) from the regions where $S h^{5}$, $S h^{\alpha S I 3 j}$, and $S h^{102}$ reside (Kamb et al., 1987) and might be associated with different (e.g., regulatory) functions.

\section{Relationship between Sh gene products and structure of $I_{A}$ channels in larval muscle}

It is now known that the $S h$ locus contains a complex transcription unit that generates multiple messages by alternative exon splicing (Kamb et al., 1988; Pongs et al., 1988; Schwarz et al., 1988). DNA sequence analysis indicates that some of the transcripts share a common central region flanked by variable $3^{\prime}$ and $5^{\prime}$ ends and may code for proteins resembling 1 of the 4 internally similar domains of $\mathrm{Na}^{+}$and $\mathrm{Ca}^{2+}$ channels (Baumann et al., 1987; Tempel et al., 1987; Kamb et al., 1988; Schwarz et al., 1988). Thus, the different $S h$ products may be separate $\mathrm{I}_{\mathrm{A}}$ channel subunits. Indeed, several species of $S h$ transcripts are each capable of generating $\mathbf{I}_{A}$-like currents in Xenopus oocyles, suggesting a homomultimeric structure (Iverson et al., 1988; Timpe et al., 1988a, b). However, it is still not known how these different $S h$ products are related to the $\mathrm{I}_{\mathrm{A}}$ channels in different nerve and muscle membranes and whether other 
transcripts from the $S h$ region still remain to be identified. Moreover, the channels expressed in oocytes may not reflect the complete structure in the natural setting.

For a number of ligand-gated channels that are known to be aggregates of different subunits, a single subunit species can form homomeric channels with apparently normal properties when expressed in oocytes or cell lines (Boulter et al., 1987; Blair et al., 1988; and other cases cited in Pritchett et al., 1988). On the other hand, expression of the rat brain $\mathrm{Na}^{+}$channel $\alpha$-subunit in oocytes requires additional RNA species to attain normal gating properties (Auld et al., 1988). Similarly, a fraction of rat brain mRNA has been used to express $\mathrm{I}_{\mathrm{A}}$ in Xenopus oocytes, but the full expression of channel kinetics and pharmacology depends on additional mRNA species (Rudy et al., 1988). Most significantly, some homomeric Sh channels expressed in oocytes are sensitive to charybdotoxin whereas the native $I_{A}$ channels are not (MacKinnon et al., 1988). Therefore, it is important to examine $I_{A}$ channels in situ to determine whether they contain heteromeric subunits with a combination of the different $S h$ products.

Functional assays in heterozygous combinations can be used to probe for nonlinear interactions between structurally dissimilar subunits generated by different mutant alterations. Leg shaking under ether anesthesia, excitatory junctional potentials (e.j.p.s) at neuromuscular junctions (unpublished data), and axonal action potentials (Tanouye et al., 1981) in heterozygotes show varying degrees of abnormality that cannot be readily quantified. The difficulty could be circumvented by direct voltagc-clamp measurements of the current, which is proportional to the density and conductance of the channels.

Strict gene-dosage effects in heterozygous combinations among leaky and amorphic alleles. The $S h^{5}$ mutation, which produces $I_{A}$ with clearly altered properties, is especially useful for detecting departures from simple gene-dosage dependence within heterozygous channels. In heterozygotes of $S h^{5}$ with amorphic mutations $S h^{M}$ and $S h^{K 8 z a}$, we found no evidence of wild-type $\mathrm{I}_{\mathrm{A}}$ but $50 \%$ of $S h^{5} \mathrm{I}_{\mathrm{A}}$. Moreover, in all possible combinations among $S h^{+}, S h^{5}, S h^{r K o I 20}, S h^{E 62}, S h^{M}$, and $S h^{K 82 a}$, the currents in heterozygotes follow closely the simple average of the parental $I_{A}$ (Figs. 4, 6, 7, and Table 1), as though only 2 populations of $I_{A}$ channels are formed, each like the parental homozygous channels, and no hybrid channels are present.

The simplest model to explain the above results is that each channel contains only one $S h$ protein which is affected by the 5 amorphic and leaky mutations. However, this monomeric model is not favored by the current molecular view of the $I_{A}$ channel being a multimer of $S h$ products (see above). On the other hand, the simple average effect can also be explained by a heteromultimeric channel in which a single copy of a $S h$ subunit subject to modification by the above 5 alleles is present along with the products of some other splicing variants not affected by these mutations. Both models do not give rise to hybrid channels in these $S h$ heterozygotes and would lead to a simple average effect.

Under different assumptions, a homomeric channel assembly could also account for the observed simple average effect: (1) Like products preferentially associate with each other such that hybrid channels do not form; or (2) hybrid channels of combinations between the 5 alleles do form but the ensemble behavior fortuitously resembles the simple average of the parental phenotypes. [In addition to $S h^{5}, S h^{r K O I 20}, S h^{E 62}$, and $S h^{M}$ may also produce altered $S h$ proteins, as indicated by immunochem- ical studies (Barbas et al., 1989) described above.] These possibilities could most definitively be resolved by single-channel measurements. Deviations in conductance and gating properties would be readily detectable because hybrid channels should constitute a majority in the population (e.g., $1 / 2$ for homodimeric and $3 / 4$ for homotrimeric form).

Departures from the simple gene-dosage effect in $\mathrm{Sh}^{\mathrm{kS133}}$ and $\mathrm{Sh}^{102}$ heterozygotes. The dominant effects of the $S h^{K S 133}$ and $S h^{102}$ mutations observed in complementation and gene duplication experiments (Figs. 8-10), especially the strong allele-specific effect of $S h^{102}$ (Fig. 10), suggest interactions among $S h$ gene products. This is also consistent with the recent observations on transgenic flies carrying a heat-inducible $S h^{102}$ gene (Gisselmann et al., 1989). In both $S h^{K S 133} / S h^{+}$and $S h^{K S I 33 / Y ; ; S h^{+}}$larvae $I_{A}$ appears normal in activation, inactivation, and kinetic properties but is reduced to about $1 / 8$ of the wild-type amplitude (Tables 1, 2, and Figs. 8, 10) The reduction in $\mathrm{I}_{\mathrm{A}}$ found in $S h^{5}$ $S h^{K S 133}, S h^{r K 0120} / S h^{K S 133}$, and $S h^{E 62} / S h^{K S 133}$ varies between ${ }^{1 / 5}$ and $1 / 8$ of the homozygous current (Table 1). In contrast, the dominant effect of $S h^{102}$ varies more clearly in an allele-specific fashion; the departure from the simple gene-dosage prediction is much greater in $S h^{E 62} / S h^{102}$ muscles and is least in $S h^{+} / S h^{102}$ (Fig. 9 and Table 1).

The exact nature of the dominant effects associated with these 2 mutations is not known. Opportunities for interactions among gene products exist during the synthesis, modification, assembly, transport, and localization of channel proteins; and the affected gene product may be altered in its functional conformation, association affinity, or production level (see Haugland, 1987, for a detailed discussion). However, the most straightforward explanation for the strong reduction of $\mathrm{I}_{\mathrm{A}}$ in $S h^{K S 133 /+}$ heterozygotes and aneuploids is that the channel consists of multiple subunits. For example, a channel containing more than 3 subunits subject to $S h^{K S / 33}$ modification could account for the probability of less than $1 / 8$ aggregates being completely normal after random association among normal and mutant subunits in $S h^{K S / 33 /+}$ heterozygotes to produce less than $1 / 8$ normal $I_{A}$ (less than $1 / 4$ of the expected averaging effect, see Table 1). Along this line of argument, the $S h^{102}$ mutation could affect the same subunit species in question if the truncated subunits (Gisselmann et al., 1989) are produced at a significantly lower amount as compared to the $S h^{K S I 33}$ product. In multimeric aggregation, this would cause $\mathrm{I}_{\mathrm{A}}$ in $S h^{+} / S h^{102}$ to be only moderately reduced as a larger number of channels would not receive a defective $S h^{102}$ subunit (cf. Fig. 9 and Tablc 1). The greater reduction observed in $S h^{r K 0120 / S h^{102}}$ and $S h^{E 62} / S h^{102}$ heterozygotes could then be explained if the $S h^{r k 0120}$ and $S h^{E 62}$ mutants produce decreased amounts of normal products.

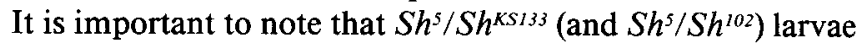
exhibit only a small, $S h^{s}$-like $\mathrm{I}_{\mathrm{A}}$ with no indication of normal $I_{\mathrm{A}}$ (see $I-V$ relations in Figs. 8 and 9). With different assumptions, several multimeric models can be proposed to explain this observation. One example is a heteromultimeric channel that contains a single copy of an $S h$ splicing variant that could be affected by $S h^{5}$ and all other alleles (including $S h^{K S 133}$ ) plus multiple copies of a different splicing variant that is subject to modification by $S h^{K S 133}$ but not by $S h^{5}$. Association among these subunits would produce no normal $\mathrm{I}_{\mathrm{A}}$, but only drastically reduced $S h^{5} \mathrm{I}_{\mathrm{A}}$ in $S h^{5} / S h^{\kappa S 133}$ heterozygotes (see Haugland, 1987, for detail). Conversely, if the condition of preferential association of like products [see assumption (1) in the previous section] is relaxed, a homomeric model, in which $S h^{5}$ and $S h^{K S I 33}$ poly- 
peptides (of the same splicing variant) are able to associate, could also produce the observed effect. It will be important to obtain additional information about the molecular lesion in $S h^{5}$ polypeptides. In contrast to the truncated product in $S h^{102}$, the $S h^{5}$ mutation confers intriguing alterations in channel gating and drug sensitivity (Haugland and $\mathrm{Wu}, 1987$ ) and interesting subunit interactions with products of other alleles.

\section{Comparisons with pupal flight muscle and sources of variation}

Our data are consistent with some of the findings in pupae and adults. In adult cervical giant fibers, addition of 2 extra copies of $S h^{+}$to one copy of $S h^{K S 133}$ in females does not restore normal action potentials (Tanouye et al., 1981; Tanouye and Ferrus, 1985), likewise indicating that the $S h^{K S 133}$ allele produces an abnormal gene product. Experiments in pupal flight muscle (Salkoff, 1983; Timpe and Jan, 1987) showed that all null $S h$ mutations, including the 4 examined here, fail to complement, yielding no detectable $\mathrm{I}_{\mathrm{A}}$ in heterozygous combinations. Timpe and Jan (1987) also suggested interactions among $S h$ gene products based on the absence of $\mathrm{I}_{\mathrm{A}}$ in $S h^{E 62} / S h^{102}$ heterozygotes.

Surprisingly, there are gross differences between the pupal and larval observations. Salkoff's (1983) voltage-clamp measurements in pupal flight muscles show that $\mathrm{I}_{\mathrm{A}}$ in aneuploid $S h^{K S 133}$ males possessing a duplication of $S h^{+}\left(Y, B^{S}\right)$ is only $1 / 2$ of the expected (normal) value (compared to $1 / 8$ in larvae) but $I_{A}$ in $S h^{+} / S h^{K S 133}$ heterozygous females is reportedly also $1 / 2$ of normal. Similarly, $\mathrm{I}_{\mathrm{A}}$ in $S h^{+} / S h^{102}$ heterozygous pupae was reported to be $52 \%$ of normal, indicating no dominant effect, whereas in $S h^{+} / S h^{k 82 a}$ pupae, $\mathrm{I}_{\mathrm{A}}$ was $83 \%$ (Timpe and Jan, 1987). In comparison, about $37 \%$ and $50 \% \mathrm{I}_{\mathrm{A}}$ were seen in larvae of these genotypes, respectively (Table 1 ). While the residual $I_{A}$ measurements in homozygous $S h^{E 62}$ and $S h^{r K 0120}$ pupae $(27 \%$ and $63 \%$, respectively) agree with larval data (about $26 \%$ and $75 \%$, respectively), the results from $S h^{E 62} / S h^{+}$and $S h^{r K 0120} / S h^{+}$differ markedly, being $84 \%$ and $136 \%$, respectively, of normal $I_{A}$ in pupae vs. about $54 \%$ and $75 \%$ in larvae (compare Table 1 with Timpe and Jan, 1987).

The sources of these variations are not known. However, at least part of these discrepancies may be artifactual. Measurements of gene-dosage effects and allelic interactions are quantitative; the amplitude of a membrane current depends on the density of ion channels and on sarcolemmal surface area. Unfortunately, the pupal muscle measurements cited above (Salkoff, 1983; Timpe and Jan, 1987) were not adjusted for fiber surface area; thus variation in animal and fiber size would increase the variation in these data. In addition, the developing pupal flight muscle may not be a suitable preparation for determinations of gene-dosage effects. Although it allows isolation of $I_{A}$ from $I_{K}$, the amplitude of $I_{A}$ is rapidly developing from 55 to $72 \mathrm{hr}$ after puparium formation. Near the end of this interval, $I_{K}$ appears (Salkoff and Wyman, 1981), but it is not known whether $I_{A}$ has reached its full development. Thus differences in developmental rates of $I_{A}$ in different strains combined with uncertainties in staging the pupal development would also increase the variation in measurements.

Nevertheless, at least part of the discrepancies may reflect true differences in the genetic control of $\mathrm{I}_{\mathrm{A}}$ between larval and pupal muscles. In one set of experiments with different doses of $S h^{+}$, Timpe and Jan (1987) have adjusted measurements using membrane capacitance. For one copy of $S h^{+}$in females (with an $S h$ deficiency), a reduction to $67 \%$ of normal $\mathrm{I}_{\mathrm{A}}$ was seen while no significant increase in $I_{A}$ was detected in pupae with 3 (wild-type females with a single duplication) and the equivalent of 4 (wild-type males with a single duplication) copies of $\mathrm{Sh}^{+}$; as though the expression of $\mathrm{Sh}^{+}$products in pupal muscle depends on a limited supply of other gene products. This is contrary to the larval data (Figs. 5,11 ) where $I_{A}$ is proportional to the $S h^{+}$dose up to the equivalent of 4 copies $\left(S h^{+} / Y ; S h^{+}\right.$ males). We cannot exclude the possibility of the presence of additional species of subunits within larval $I_{A}$ channels, for instance, a $S h$ product not affected by the mutations examined or a nonlimiting product of a gene outside of the $S h$ locus (see above).

\section{Genetic basis for the diversity of $\mathrm{K}^{+}$channels}

Since the various $S h$ products differ in their distribution in different body parts (Schwarz et al., 1988), they may not be present in a fixed stoichiometry in all tissues and may contribute to different subtypes of $I_{A}$ channels or even different types of $\mathrm{K}^{+}$channels. The difference in dosage dependence on $S h^{+}$could indicate that the number of $I_{A}$ channels is limited only by the amount of $S h$ products in larval muscle, whereas it is restricted by the products of other loci in pupal muscle. There are also intriguing differences in the effects of certain $S h$ mutations on the properties of $I_{A}$ in these 2 sets of muscles. In $S h^{5}$ pupal muscle, $I_{A}$ was reported to show normal peak amplitude but abnormally rapid kinetics of inactivation and recovery (Salkoff, 1983). In striking contrast, the $S h^{5}$ mutation greatly alters the voltage dependence of $I_{A}$ in larval muscle (Fig. 2), actually slowing its kinetics of activation and inactivation (Haugland, 1987). Furthermore, as previously pointed out (Wu and Haugland, 1985; Timpe and Jan, 1987), the $S h^{\text {rKOI2O }}$ mutation exerts markedly different effects on nerve and muscle membranes. Although it causes in larval nerve terminals aberrations nearly as extreme as $S h^{K S I 33}$ (Ganetzky and Wu, 1983), voltage-clamp studies on larval (Wu and Haugland, 1985, and Fig. 2) and pupal (Timpe and Jan, 1987) muscles indicate only mild reductions in $I_{A}$ amplitude. [There has been some confusion about $S h^{r K 0120}$ strains. The one that was reported to show no $\mathrm{I}_{\mathrm{A}}$ in pupal muscle (Salkoff

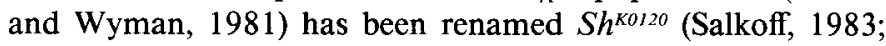
Timpe and Jan, 1987) and should not be confused with the present discussion.] The picture is further complicated by recent patch-clamp studies which showed that certain inactivating current resembling $I_{A}$ in cultured neurons remains intact in the presence of either the $S h^{K S 133}$ mutation (Solc et al., 1987) or a deletion of the $S h$ locus (Baker and Salkoff, 1988).

The above discrepancies suggest that $I_{A}$ channels in different excitable membranes may be regulated by other genes outside of the $S h$ locus as well (see Butler et al., 1989). In fact, mutations of 2 different loci, eag (ether á go-go) (Wu et al., 1983; Ganetzky and $\mathrm{Wu}, 1986$; Y. Zhong and $\mathrm{Wu}$, unpublished data) and $H k$ (Hyperkinetic) (Wu and Ganetzky, 1986; Wu, 1988; Stern and Ganetzky, 1989) have been suggested to alter $I_{A}$ and also other $\mathrm{K}^{+}$currents. Taken together, these results suggest that, as previously proposed in a combinatorial hypothesis (Wu and Haugland, 1985; Wu and Ganetzky, 1986), diversity of $\mathrm{K}^{+}$channel types may arise from combinations of common, as well as distinct, structural or regulatory components. In this respect, the possibility that different $S h$ proteins may be involved in generating $I_{A}$ channel subtypes and even contribute to other types of $\mathrm{K}^{+}$channels (Iverson et al., 1988; Pongs et al., 1988; Timpe et al., 1988b) is cspccially intriguing. Considering the large number of $S h$ products so far identified, combinations of different 
$S h$ products and those of other genes could give rise to a great diversity of channel subtypes.

\section{References}

Auld, V. J., A. L. Goldin, D. S. Krafte, J. Marshall, J. M. Dunn, W. A. Catterall, H. A. Lester, N. Davidson, and R. J. Dunn (1988) A rat brain $\mathrm{Na}^{+}$channel with novel gating properties. Neuron 1:449-461.

Baker, K. H., and L. Salkoff (1988) Diverse transient $\mathrm{K}^{+}$currents in Drosophila neurons deleted for the Shaker locus predict other genes homologous to Shaker. Soc. Neurosci. Abstr. 14: 455.

Barbas, J. A., N. Rubio, E. Pedroso, and A. Ferrus (1989) Antibodies against the potassium channcls of Drosophila rccognize products across species. Mol. Brain Res. 5: 171-176.

Baumann, A., I. Krah-Jentgens, R. Müller, F. Müller-Holtkamp, R. Seidel, N. Kecskemethy, J. Casal, A. Ferrus, and O. Pongs (1987) Molecular organization of the maternal effect region of the Shaker complex of Drosophila: Characterization of an $\mathbf{I}_{\mathbf{A}}$ channel transcript with homology to vertebrate $\mathrm{Na}^{+}$channel. EMBO J. 6: 3419-3429.

Blair, L. A. C., E. S. Levitan, J. Marshall, V. E. Dionne, and E. A. Barnard (1988) Single subunits of the GABA A $_{A}$ receptor form ion channels with properties of the native receptors. Science 242: 577579.

Boulter, J., J. Connolly, E. Deneris, D. Goldman, S. Heinemann, and J. Patrick (1987). Functional expression of two neuronal nicotinic acetylcholine receptors from cDNA clones identifies a gene family. Proc. Natl. Acad. Sci. USA 84: 7763-7767.

Butler, A., A. Wei, K. Baker, and L. Salkoff (1989) A family of putative potassium channel genes in Drosophila. Science 243: 943-947.

Crossley, A. C. (1978) The morphology and development of the Drosophila muscular system. In Genetics and Biology of Drosophila, M. Ashburner and T. R. F. Wright, eds., Vol. 2b, pp. 449-559, Academic, New York.

Elkins, T., B. Ganetzky, and C.-F. Wu (1986) A Drosophila mutation that eliminates a calcium-dependent potassium current. Proc. Natl. Acad Sci. USA 83: 8415-8419.

Fieller, E. C. (1932) Cited in Fundamental Formulas of Physics, D. H. Menzel, ed., Vol. 1, p. 140, Dover, New York.

Ganetzky, B., and C.-F. Wu (1982) Drosophila mutants with opposing effects on nerve excitability: Genetic and spatial interactions in repetitive firing. J. Ncurophysiol. 47: 501-514.

Ganetzky, B., and C.-F. Wu (1983) Neurogenetic analysis of potassium currents in Drosophila: Synergistic effects on neuromuscular transmission in double mutants. J. Neurogenet. 1: 17-28.

Ganetzky, B., and C.-F. Wu (1986) Neurogenetics of membrane excitability in Drosophila. Annu. Rev. Genet. 20: 13-44.

Gho, M., and A. Mallart (1986) Two distinct calcium-activated potassium currents in larval muscle fibers of Drosophila melanogaster. Pflügers Arch. 407: 526-533.

Gisselmann, G., S. Sewing, B. W. Madsen, A. Mallart, A. Angaut-Petit, F. Müller-Holtkamp, A. Ferrus, and O. Pongs (1989) The interference of truncated with normal potassium channel subunits leads to abnormal behavior in transgenic Drosophila melanogaster. EMBO J. 8: 2359-2364.

Haugland, F. N. (1987) A voltage-clamp analysis of membrane potassium currents in larval muscle fibers of the Shaker mutants of Drosophila, Ph.D. thesis, University of Iowa, Iowa City.

Haugland, F. N., and C.-F. Wu (1986) Gene-dosage effects on a $\mathrm{K}^{\prime}$ current in Drosophila. Biophys. J. 49: 168a.

Haugland, F. N., and C.-F. Wu (1987). Concomitant alteration of potassium channel gating and pharmacology in a Shaker mutant of Drosophila. Abstr. Soc. Neurosci. 13: 150.

Iverson, L. E., M. A. Tanouye, H. A. Lester, N. Davidson, and B. Rudy (1988) A-type potassium channels expressed from Shaker locus cDNA. Proc. Natl. Acad. Sci. USA 85: 5723-5727.

Jan, L. Y., and Y. N. Jan (1976) Properties of the larval neuromuscular junction in Drosophila melanogaster. J. Physiol. (Lond.) 262: 215236.

Jan, Y. N., L. Y. Jan, and M. J. Dennis (1977) Two mutations of synaptic transmission Drosophila. Proc. R. Soc. Lond. Biol. 198: 87108.

Kamb, A., L. E. Iverson, and M. A. Tanouye (1987) Molecular characterization of Shaker, a Drosophila gene that encodes a potassium channel. Cell 50: 405-413.

Kamb, A., J. Tseng-Crank, and M. A. Tanouye (1988) Multiple prod- ucts of the Drosophila Shakergene may contribute to potassium channel diversity. Neuron $1: 421-430$.

Kaplan, W. D., and W. E. Trout, III (1969) The behavior of 4 neurological mutants of Drosophila. Genetics 61: 399-409.

Lindsley, D. L., and E. H. Grell (1968) Genetic variations of Drosophila melanogaster, Publ. No. 627, Carnegie Inst., Washington.

MacKinnon, R., P. H. Reinhart, and M. M. White (1988) Charybdotoxin block of Shaker $\mathrm{K}^{+}$channels suggests that different types of $\mathrm{K}^{+}$channels share common structural features. Neuron 1:997-1001.

Papazian, D. M., T. L. Schwarz, B. L. Tempel, Y. N. Jan, and L. Y. Jan (1987) Cloning of genomic and complementary DNA from Shaker, a putative potassium channel gene from Drosophila. Science 237: 749-753.

Papazian, D. M., T. L. Schwarz, B. L. Tempel, L. C. Timpe, and L. Y. Jan (1988) Ion channels in Drosophila. Annu. Rev. Physiol. 50: 379-394.

Pongs, O., N. Kecskemethy, R. Müller, I. Krah-Jentgens, A. Baumann, H. H. Kiltz, I. Canal, S. Llamazares, and A. Ferrus (1988) Shaker encodes a family of putative potassium channel proteins in the nervous system of Drosophila. EMBO J. 7: 1087-1096.

Pritchett, D. B., H. Sontheimer, C. M. Gorman, H. Kettenmann, P. H. Seeburg, and P. R. Schofield (1988) Transient expression shows ligand gating and allosteric potentiation of $\mathrm{GABA}_{\mathrm{A}}$ receptor subunits. Science 242: 1306-1308.

Rudy, B., J. H. Hoger, H. A. Lester, and N. Davidson (1988) At least two mRNA species contribute to the properties of rat brain A-type potassium channels expressed in Xenopus oocytes. Neuron 1: 649658.

Salkoff, L. (1983) Genetic and voltage clamp analysis of a Drosophila potassium channel. Cold Spring Harbor Symp. Quant. Biol. 48: 221231.

Salkoff, L., and M. A. Tanouye (1986) Genetics of ion channels. Physiol. Rev. 66: 301-329.

Salkoff, L., and R. Wyman (1981) Genetic modification of potassium channels in Drosophila Shaker mutants. Nature 293: 228-230.

Schwarz, T. L., B. L. Tempel, D. M. Papazian, Y. N. Jan, and L. Y. Jan (1988) Multiple potassium-channel components are produced by alternative splicing at the Shaker locus in Drosophila. Nature 331 . 137-142.

Singh, S., and C.-F. Wu (1989) Complete separation of four potassium currents in Drosophila. Neuron 2: 1325-1329.

Solc, D. K., W. N. Zagotta, and R. W. Aldrich (1987) Single-channel and genetic analyses reveal two distinct A-type potassium channels in Drosophila. Science 236: 1094-1098.

Stern, M., and B. Ganetzky (1989) Altered synaptic transmission in Drosophila Hyperkinetic mutants. J. Neurogenet. (in press).

Stewart, B., and J. Merriam (1980) Dosage compensation. In Genetics and Biology of Drosophila, M. Ashburner and T. R. F. Wright, eds., Vol. 2, pp. 107-140, Academic, New York.

Tanouye, M. A., and A. Ferrus (1985) Action potentials in normal and Shaker mutant Drosophila. J. Neurogenet. 2: 253-271.

Tanouye, M. A., A. Ferrus, and S. C. Fujita (1981) Abnormal action potentials associated with the Shaker locus of Drosophila. Proc. Natl. Acad. Sci. USA 78: 6548-6552.

Tanouye, M. A., C. A. Kamb, L. E. Iverson, and L. Salkoff (1986) Genetics and molecular biology of ionic channels in Drosophila. Annu. Rev. Neurosci. 9: 255-276.

Tempel, B. L., D. M. Papazian, T. L. Schwarz, Y. N. Jan, and L. Y. Jan (1987) Sequence of a probable potassium channel component encoded at Shaker locus of Drosophila. Science 237: 770-775.

Timpe, L. C., and L. Y. Jan (1987) Gene dosage and complementation analysis of the Shaker locus in Drosophila. J. Neurosci. 7: 1307-1317.

Timpe, L. C., Y. N. Jan, and L. Y. Jan (1988a) Four cDNA clones from the $S h$ locus of Drosophila induce kinetically distinct A-type potassium currents in Xenopus oocytes. Neuron 1: 659-667.

Timpe, L. C., T. L. Schwarz, B. L. Tempel, D. M. Papazian, Y. N. Jan, and L. Y. Jan (1988b) Expression of functional potassium channels from Shaker cDNA in Xenopus oocytes. Nature 331: 143-145.

Wu, C.-F. (1988) Neurogenctic studics of Drosophila central nervous system neurons in culture. In Cell Culture Approaches to Invertebrate Neurosciences, D. Beadle, G. Less, and S. B. Kater, eds., pp. 149187, Academic, London.

Wu, C.-F., and B. Ganetzky (1986) Genes and ionic channels in Drosophila. In Ion Channels in Neural Membranes, J. M. Ritchie, R. D. Keynes, and L. Bolis, eds., pp. 407-423, Liss, New York. 
Wu, C.-F., and F. N. Haugland (1985) Voltage clamp analysis of membrane currents in larval muscle fibers of Drosophila: Alteration of potassium currents in Shaker mutants. J. Neurosci. 5: 2626-2640. Wu, C.-F., B. Ganetzky, F. N. Haugland, and A.-X. Liu (1983) Potassium currents in Drosophila: Different components affected by mutations of two genes. Science 220: 1076-1078.
Zagotta, W. N., M. S. Brainard, and R. W. Aldrich (1988) Singlechannel analysis of four distinct classes of potassium channels in Drosophila muscle. J. Neurosci. 8: 4765-4779. 